OPEN ACCESS

Edited by:

Julia Maria Schulze-Hentrich,

Tübingen University Hospital,

Germany

Reviewed by:

Anja Lok,

Academic Medical Center, University of Amsterdam, Netherlands

Ilan A. Kerman,

Virginia Tech Carilion School of Medicine and Research Institute,

United States

*Correspondence:

Olivia Engmann

olivia.engmann@med.uni-jena.de

Specialty section:

This article was submitted to

Neurogenomics,

a section of the journal

Frontiers in Neuroscience

Received: 13 July 2020

Accepted: 09 November 2020

Published: 07 December 2020

Citation:

Aly J and Engmann O (2020) The

Way to a Human's Brain Goes

Through Their Stomach: Dietary

Factors in Major Depressive Disorder.

Front. Neurosci. 14:582853.

doi: 10.3389/fnins.2020.582853

\section{The Way to a Human's Brain Goes Through Their Stomach: Dietary Factors in Major Depressive Disorder}

\author{
Janine Aly ${ }^{1}$ and Olivia Engmann ${ }^{2 *}$ \\ ${ }^{1}$ Faculty of Medicine, Friedrich Schiller Universität, Jena, Germany, ${ }^{2}$ Institute for Human Genetics, Jena University Hospital, \\ Jena, Germany
}

Globally, more than 250 million people are affected by depression (major depressive disorder; MDD), a serious and debilitating mental disorder. Currently available treatment options can have substantial side effects and take weeks to be fully effective. Therefore, it is important to find safe alternatives, which act more rapidly and in a larger number of patients. While much research on MDD focuses on chronic stress as a main risk factor, we here make a point of exploring dietary factors as a somewhat overlooked, yet highly promising approach towards novel antidepressant pathways. Deficiencies in various groups of nutrients often occur in patients with mental disorders. These include vitamins, especially members of the B-complex (B6, B9, B12). Moreover, an imbalance of fatty acids, such as omega-3 and omega-6, or an insufficient supply with minerals, including magnesium and zinc, are related to MDD. While some of them are relevant for the synthesis of monoamines, others play a crucial role in inflammation, neuroprotection and the synthesis of growth factors. Evidence suggests that when deficiencies return to normal, changes in mood and behavior can be, at least in some cases, achieved. Furthermore, supplementation with dietary factors (so called "nutraceuticals") may improve MDD symptoms even in the absence of a deficiency. Non-vital dietary factors may affect MDD symptoms as well. For instance, the most commonly consumed psychostimulant caffeine may improve behavioral and molecular markers of MDD. The molecular structure of most dietary factors is well known. Hence, dietary factors may provide important molecular tools to study and potentially help treat MDD symptoms. Within this review, we will discuss the role of dietary factors in MDD risk and symptomology, and critically discuss how they might serve as auxiliary treatments or preventative options for MDD.

Keywords: major depressive disorder, dietary factors, antidepressants, vitamins, fatty acids, caffeine, minerals

\section{MDD - A MAJOR HEALTH CHALLENGE IN MODERN SOCIETIES}

Anhedonia, feelings of guilt and worthlessness, circadian alterations and a lack of motivation are only some symptoms of major depressive disorder (MDD; Krishnan and Nestler, 2010; Edgar and Mcclung, 2013). In 2016, the global prevalence of MDD amounted to 268.2 million people worldwide and accounted for 44.2 million life-years lost to disability (Vos et al., 2017). Major depressive disorder is the main cause for suicide and therefore potentially lethal (Bebbington, 2001). 
The MDD-related loss in productivity at work costs governments annually billions of dollars [e.g., Switzerland: 8.2 billion Euros (2008) (Tomonaga et al., 2013); United States: 210.5 billion dollars (2010) (Greenberg et al., 2015)]. Major depressive disorder is now one of the largest categories of health care expenditure, in part due to patients, which are resistant to currently available treatments (Mrazek et al., 2014). In contrast to many formerly life-threatening diseases, which have been successfully controlled due to hygiene, vaccination and antibiotics, the risk for MDD is on the rise in many modern societies (Hidaka, 2012). Hence, the research field of MDD is becoming increasingly recognized.

Throughout the years, various risk factors for MDD were described. Besides a genetic predisposition, multiple environmental risk factors have been determined. These include traumatic events in early or adult life and chronic stress (Mann and Currier, 2006). Hence, a complex interplay between social, psychological and genetic factors seems to be responsible for MDD.

Perhaps due to the multifactorial nature of this illness, a large population of MDD patients does not fully respond to current pharmacological antidepressant treatments (Krystal et al., 2019), which moreover take weeks to reach their full efficacy (Harmer et al., 2017). Nevertheless, the choice in treatment options has been greatly expanded during the last decades. Despite a good amount of serendipity in antidepressant research, over the last years, various treatments have been developed based on functional hypotheses of MDD: Medications that increase the amount of monoamines, suppress an overactive hypothalamicpituitary-adrenal (HPA) axis or anti-inflammatory drugs are used to counteract MDD (Ferrari and Villa, 2017), albeit more unconventional paths such cholinergic and opioid signaling are under investigation as well (Papakostas and Ionescu, 2015). Although those antidepressants evoke a response at the molecular level within hours, it often takes weeks before a therapeutic effect takes place. A possible alternative, which is mainly used in therapy-resistant cases, lies in the fast-acting compound ketamine (Krystal et al., 2019). This drug, originally used as a sedative and abused as a psychoactive substance, has an antidepressant effect that occurs within hours and lasts for several days. Consequently, it is a fast-acting and highly effective drug against MDD. However, due to its abuse potential, the use of ketamine is limited and not practicable as a long-term treatment (Andrade, 2017).

Alternatively, there are non-pharmaceutical interventions available. Light therapy, sleep restriction, as well as psychotherapeutic interventions such as interpersonal therapy and cognitive behavioral therapy can cause some improvements in MDD (Markowitz and Weissman, 2004; Golden et al., 2005; Anthes, 2014; Murphy and Peterson, 2015). Indeed, cognitive behavioral therapy has been shown to be as effective as pharmacological interventions (Weitz et al., 2015). Other non-pharmacological interventions in use for MDD are electroconvulsive therapy, trancranical magnetic stimulation and vagus nerve stimulation, all of which can be effective in refractory cases (O'Reardon et al., 2006). However, some of these treatments come at a considerably larger cost to healthcare providers, require invasive protocols or remain stigmatized (O'Reardon et al., 2006; Ross et al., 2019). In consequence, despite their health-benefits, non-pharmacological interventions are often not sufficiently available.

Interestingly, despite accumulating evidence for a link between MDD and nutrition, dietary factors as potential pharmacological tools for MDD treatment have been largely overlooked. Hence, in this review we will make a point, that more effort should be invested in this direction: Deficiencies in numerous nutrients, including vitamins, minerals or fatty acids, are more commonly observed in patients with mental disorders. By correcting dietary deficiencies, both behavioral changes and an improvement in mood may be achieved (Rao et al., 2008). Furthermore, preliminary evidence suggests that supplementation with certain dietary factors might improve MDD-symptoms even in non-deficient populations. Additionally, non-vital nutritional factors such as caffeine may positively affect MDD-symptomology (Lucas, 2011). Supplementation with dietary factors may be a safe, cost-effective and easily implementable therapeutic approach. Moreover, dietary factors provide well-characterized single-molecule tools to unravel previously unknown molecular pathways underlying MDD in animal models. In this review, we will discuss the role of selected dietary factors in MDD and we will critically examine how they might serve as an adjunctive treatment or preventative option for MDD.

\section{DEPRESSION - AN ILLNESS WITH MANY CAUSES}

The brain areas affected in MDD are largely known. These comprise regions involved in cognitive and emotional processing, including the prefrontal cortex, hippocampus, hypothalamus and amygdala as well as the brain reward system (nucleus accumbens, ventral tegmental area, habenula). Nevertheless, the exact pathophysiological origin of the disease remains unclear. Up to now, various hypotheses about the molecular cause of MDD have been established:

1.) The monoamine hypothesis is one of the best-known theories on the molecular origins of MDD: The underlying assumption is that a depletion of monoamines is responsible for MDD-symptoms. Monoamines such as norepinephrine (NE), serotonin (5-HT), and dopamine all play a crucial role in the coordination of mood, motivation, and circadian rhythms - processes, which are often affected during MDD (Hamon and Blier, 2013). Several studies have provided causal evidence that an insufficient supply or an increased degradation of monoamines, and dysregulation of subsequent signal transduction pathways, cause MDD-like symptoms (Meyer et al., 2006; Prins et al., 2011; Ferrari and Villa, 2017).

2.) Growth factors are associated with MDD as well. In particular, the brain-derived neurotrophic factor (BDNF) is strongly correlated with antidepressant action (Bjorkholm and Monteggia, 2016). Brain-derived neurotrophic factor 
is widely expressed in the central nervous system and is important for neuronal maturation, but also for synapse formation and synaptic plasticity. The activity of $\mathrm{BDNF}$ is regulated by the cyclic AMP response element binding protein (CREB), which binds to its promoter region. Brain-derived neurotrophic factor modulates tropomyosin receptor kinase B receptors (TRKB), thereby influencing neurotransmission and synaptic plasticity. A transcriptional dysregulation of BDNF and TRKB has been commonly observed in MDD (Dwivedi et al., 2003; Qi et al., 2015; Bjorkholm and Monteggia, 2016) and in suicide completers (Maussion et al., 2014). This suggests that the TRKB-pathway may be an interesting target for possible treatment approaches. Lesser known growth factors implicated in MDD are fibroblast growth factor, vascular endothelial growth factor, insulin-like growth factor and glial cell-line derived neurotrophic factor (Levy et al., 2018).

3.) Another hypothesis implicates the hypothalamuspituitary-adrenal (HPA) axis and specifically addresses the link between chronic stress and MDD-risk (Pariante and Lightman, 2008). Through a hormonal cascade, stress increases the secretion of adrenal glucocorticoids. Glucocorticoids are involved in the control of neuronal survival, neurogenesis, synaptic plasticity and hippocampal size, linking brain function and stress (McEwen, 2017). Intriguingly, glucocorticoids can inhibit their own release via a negative feedback loop, which is thought to be impaired in MDD (Pariante and Lightman, 2008). Chronic stress can lead to a disruption of this negative feedback loop. The result is a frequently observed overactivation of the HPA axis in MDD-patients (Bhagwagar et al., 2003; Bao and Swaab, 2010).

4.) Furthermore, there is evidence for a link between inflammation and MDD (Miller et al., 2009). Analysis of peripheral blood from MDD-patients revealed elevated levels of inflammatory biomarkers, including cytokines, chemokines, and adhesion molecules (Howren et al., 2009). These molecules can cross the blood-brain barrier, where they interact with different brain regions involved in monoamine synthesis, neuroendocrine regulation, and neuronal plasticity, which are heavily implicated in MDD (Ferrari and Villa, 2017). Since inflammation affects monoamines and the HPA axis, an interaction between many different factors is likely to contribute to MDD.

5.) Cellular damage due to excitotoxicity, changed gene expression, chronic stress (e.g., due to nitric oxide) or elevated inflammation in the brain can also be observed during aging. Symptoms that are associated with MDD, including cognitive decline, fatigue, or sleep disturbances, often occur in aged populations, especially in the context of neurodegenerative diseases. Furthermore, MDD patients have a shorter average life expectancy. This connection led to the hypothesis that MDD is a condition of accelerated brain aging (Heuser, 2002; Wolkowitz et al., 2010; Kinser and Lyon, 2013). Postmortem examination of the brains of MDD patients revealed anatomical changes consistent with this idea, including a reduction in gray matter volume (Grieve et al., 2013; Zhao et al., 2014), neuronal loss (Banasr et al., 2011), and impaired cerebral blood flow (Burrage et al., 2018). On a molecular level, MDD patients tend to show a reduced telomere length (Monroy-Jaramillo et al., 2018), altered DNA methylation (Peña and Nestler, 2018) and accumulated damage in mtDNA (Kasahara and Kato, 2018), which all have been implicated in aging (Booth and Brunet, 2016). However, it is currently unclear, whether these alterations contribute to MDD or are the result of it.

6.) MDD can be, at least in part, understood as a metabolic disorder. There is a bidirectional comorbidity between MDD and obesity (Milaneschi et al., 2019). Abovementioned alterations in the HPA-axis and inflammation as well as genetics may be shared risk factors for both, MDD and metabolic changes. However, more direct metabolic regulators may affect MDD as well. For instance, the feeding hormone leptin has antidepressant-like effects in mouse models (Yamada-Goto et al., 2011; Garza et al., 2012), while deletion of the leptin receptor in certain brain areas can induce resistance to common antidepressants (Guo and Lu, 2014). There may also be an association between insulin resistance and MDD in patients (Kan et al., 2013). The microbiome, which is critical in both, regulating nutrient uptake and fighting inflammation, appears to be affected in MDD patients as well (Jiang et al., 2015; Zhernakova et al., 2016; Lin et al., 2017). However, secondary effects due to antidepressant medications need to be ruled out when interpreting those studies. Given those contributing factors, it is intriguing to speculate that MDD may be a manifestation of a metabolic syndrome. Interestingly exercise, a main regulator of metabolism, has been repeatedly shown to ameliorate MDD symptoms (Carek et al., 2011).

7.) Twin studies suggest that MDD is only $37 \%$ heritable (Kendler, 2001). Hence, there is a strong environmental component to this disorder. Epigenetic mechanisms can modify chromatin without affecting the DNA-sequence and are known to integrate environmental risk factors and genetic propensity to ultimately affect gene transcription. There is accumulating evidence that a variety of chromatin modifications is altered both, in peripheral tissue (typically blood), and postmortem in the brains of MDD patients (Penner-Goeke and Binder, 2019).

DNA methylation is thought to be the most stable and longlasting chromatin modification. Hence, MDD risk factors such as early life trauma may alter DNA methylation patterns to shape disease risk later in life (Matosin et al., 2017). In monozygotic twin studies, DNA methylation patterns were associated with MDD risk later in life (Palma-Gudiel et al., 2020). Of the many DNA methylation changes described in MDD, changes in the BDNF gene have been most often replicated (Chen et al., 2017; Penner-Goeke and Binder, 2019).

Not only DNA, but histones, too, can be methylated albeit by a different enzymatic machinery. Of the plethora of histone residues, changes in the repressive marks $\mathrm{H} 3 \mathrm{~K} 4 \mathrm{me} 3$ 
and $\mathrm{H} 3 \mathrm{~K} 27 \mathrm{me} 3$ have been described in MDD patients and suicide victims (Ernst et al., 2009; Chen et al., 2011; Fiori et al., 2012). Moreover, histone acetylation changes have been observed postmortem at the enhancer mark $\mathrm{H} 3 \mathrm{~K} 14 \mathrm{ac}$ (Covington et al., 2009). Accordingly, changes in histone deacetylase enzymes HDAC2 and SIRT1 have been detected in postmortem brain tissues of MDD patients (Covington et al., 2009; Kishi et al., 2010; Ledford, 2015). Rodent models of MDD have shown an even larger number of changed histone marks, suggesting that there may be a specific histone foot print induced by chronic stress (Nestler et al., 2015). Besides "classical" epigenetic modifications on histones and DNA, a large number of micro-RNA changes in peripheral tissue has been implicated in MDD. Of these, miR-132 has most often been replicated (Yuan et al., 2018). Furthermore, a reduced telomere length has been observed in patients with MDD (Henje Blom et al., 2015; Monroy-Jaramillo et al., 2018) and bipolar depression (BD; Squassina et al., 2017; Powell et al., 2018). Telomeres are relevant to maintain genome stability and their shortening is typically associated with aging in mitotic cells. Furthermore, mutations in mitochondrial DNA have been detected in patients suffering from MDD and BD (Kato, 2017; Czarny et al., 2018).

The epigenetics field is highly dynamic. New histone modifications such as dopaminylation and homocysteinylation are still being discovered (Zhang et al., 2018; Lepack et al., 2020). It is very likely that additional chromatin marks that are just being described or are currently still unknown, play a role in MDD as well.

All of the MDD hypotheses mentioned above are interconnected. For instance, changed DNAme in the BDNF pathway connects epigenetic and growth factor aspects (Bakusic et al., 2017), while increased inflammation and oxidative stress can lead to epigenetic changes such as reduced telomere length and mtDNA mutations (Czarny et al., 2018).

\section{VITAMINS AND THEIR ROLE IN DEPRESSION}

\section{Vitamin B6 Is an Essential Puzzle Piece for Neurotransmitter Production}

Pyridoxine, pyridoxal, and pyridoxamine are three related, naturally occurring isoforms that are grouped together under the name of vitamin B6. They can be obtained from a variety of food, including meat, dairy products, grains, nuts, vegetables, and certain fruits. Once absorbed in the small intestine, all isoforms can be converted into pyridoxal $5^{\prime}$-phosphate (PLP), the active metabolite of B6, which modulates more than 150 enzymatic reactions within the body. In consequence it is involved in several processes related to mental function and mood as well (Hvas et al., 2004; Mikkelsen et al., 2016).

The production of serotonin (5-hydroxytryptamine, 5-HT), a neurotransmitter that is depleted during MDD, takes place primarily in the raphe nuclei of the brain. Although it is possible to ingest 5-HT with the diet, the molecule itself cannot cross the blood-brain barrier. However, tryptophan (TRP), the precursor of 5-HT, can enter the brain. Two enzymes within serotonergic neurons are then responsible for the conversion of TRP into 5HT: Hydroxylation of TRP is induced by tryptophan hydroxylase 2 (TPH2), followed by decarboxylation through aromatic Lamino acid decarboxylase (AADC) (Figure 1). Pyridoxal 5' phosphate acts as a cofactor for AADC and is hence crucial for the synthesis of 5-HT in the brain. Therefore, a vitamin B6 deficiency could lead to reduced 5-HT levels and may thus be a potential risk factor for MDD (Höglund et al., 2019; Mikkelsen et al., 2016). Furthermore, low levels of PLP may be associated with stress (McCarty, 2000). Accordingly, supplementation with both, vitamin B6 and TRP, increases 5-HT neurotransmission (Shabbir et al., 2013).

Vitamin B6 supplementation improved MDD-symptoms in an aged cohort and vitamin B6 levels generally correlated with MDD severity (Moore et al., 2019). Furthermore, lower vitamin B6 intake correlated with disease severity in female MDD-patients (Kafeshani et al., 2019). The diagnosis of vitamin B6 deficiency in MDD patients and the subsequent change in diet could therefore serve as a treatment complementary to drug therapy.

Vitamin B6 is not only part of the 5-HT synthesis pathway, it also plays a role in the kynurenine pathway (Figure 1). Pyridoxal $5^{\prime}$-phosphate serves as a co-factor for both, kynurenine aminotransferase and kynurenine hydroxylase. The products of this pathway are the neuroprotective metabolite kynurenic acid (KYNA) and the neurotoxic substance quinolinic acid (QUIN). Normally, the effects of KYNA and QUIN are well balanced. However, during chronic stress or inflammation, the equilibrium can be shifted towards QUIN. Being an agonist of $N$-methylD-aspartate (NMDA) receptors, high concentrations of QUIN can induce excitotoxicity (Guillemin, 2012) and may contribute to the neural damage often observed in MDD-brains (Miura et al., 2008; Meier et al., 2016). Elevated glutamate concentrations can also lead to oxidative stress and mitochondrial damage via an increase in nitric oxide synthases (nNOS, iNOS) (Dawson et al., 1991), which can contribute to inflammatory processes. An upregulation of inflammatory mediators is not only induced by QUIN but also occurs in the absence of vitamin B6 (Ueland et al., 2017).

Pyridoxal $5^{\prime}$-phosphate is a co-factor for a variety of enzymes that affect the homocysteine pathway (see below) ( $\mathrm{Wu}$ and Lu, 2012). Vitamin B6 may therefore indirectly alter chromatin marks such as DNA- and histone methylation as well as chromatin structure.

Furthermore, vitamin B6 is an important metabolite in the production of gamma amino butyric acid (GABA) out of its precursor glutamate (McCarty, 2000; Jung et al., 2019). A decreased turnover of GABA due to vitamin B6 deficiency could therefore result in a lack of inhibitory feedback in the brain. This mechanism could further amplify the damage caused by increased glutamate levels.

$\mathrm{NF} \mathrm{B}$, a transcription factor involved in the production of cytokines and cell survival, is influenced by vitamin B6 as well. It modulates the immune response of macrophages and is suppressed in the presence of PLP (Yanaka et al., 2005). The resulting inflammatory response activates the kyurenine 


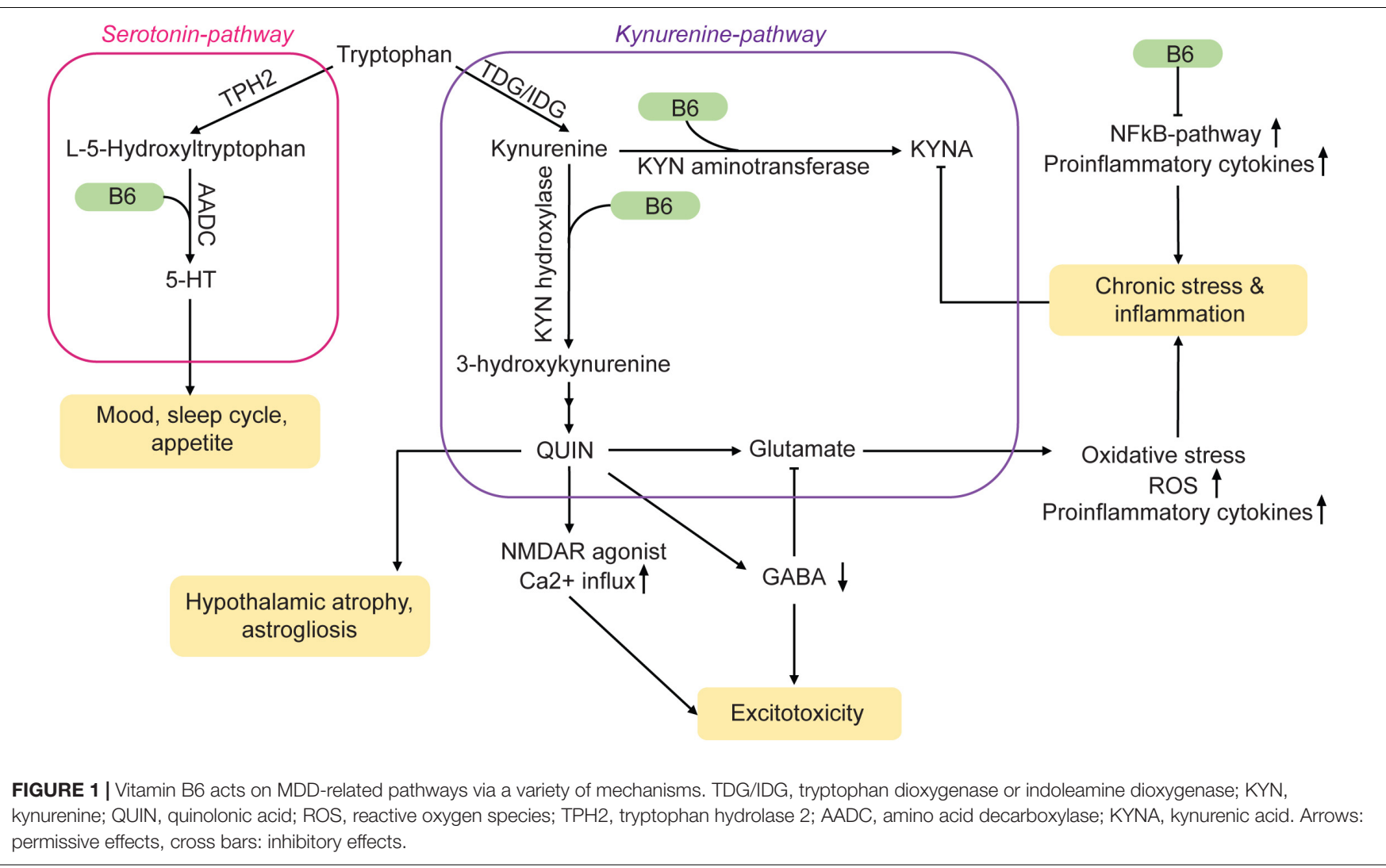

pathway further (Ueland et al., 2017). Therefore, vitamin B6 has key functions in monoamine synthesis and is involved in the regulation of the immune response to various stressors. A misregulation of these processes due to insufficient supply can lead to 5-HT depletion and increased inflammation, which links vitamin B6 deficiency to a variety of risk factors for MDD.

Prophylactic intake of vitamin B6 did not reduce the risk of MDD among older women in a 7-year longitudinal study (Okereke et al., 2015). However, in this study, potential prior deficiencies have not been investigated, which impedes the interpretation of the data. In contrast, vitamin B6 appeared to rapidly ameliorate symptoms such as low mood in young MDD-patients when the disease was already present, even though in this study, deficiencies have not been assessed either (Tsujita et al., 2019). Furthermore, the beneficial properties of vitamin B6 have been demonstrated in a variety of non-deficient rodent studies. For instance, vitamin B6 improved behavioral measures in forced swim and sucrose preference tests in the dexamethasone mouse model of depression (Mesripour et al., 2019). Additionally, when co-administered, vitamin B6 enhanced the effect of antidepressants clomipramine and venlafaxine but not fluoxetine in the forced swim test (Mesripour et al., 2017). However, further research is required to make more precise predictions on the efficacy of vitamin B6 supplements in MDD. For instance, in human cohorts, an undiagnosed vitamin B6 deficiency or an interaction with other risk factors such as stress and comorbid diseases should be taken into consideration when designing future studies. In mouse models, the effect of vitamin
B6 on the susceptibility to chronic stress should be investigated, paying special attention to chronic versus fast-acting effects of vitamin B6. Furthermore, the impact of vitamin B6 on manic states in $\mathrm{BD}$ is insufficiently investigated. For instance, a case report suggests that vitamin B6, at least in combination with other substances, may induce secondary mania (Chaturvedi and Upadhyaya, 1988). However, it appears that vitamin B6 may have a positive effect on lithium-induced tremor in patients (Dias Alves et al., 2017).

\section{Two Main Players Within the One Carbon Metabolism - Vitamin B9 and B12}

Two other members of the vitamin B-complex are often associated with MDD. Vitamin B9 (folate) is primarily obtained from plant-based nutrients, while vitamin B12 (cobalamin) is only synthesized by bacteria and enriched across the food chain in animal products and certain algae or fungi. Together they are two interdependent nutrients, which are involved in the regulation of various essential processes, including the methionine cycle, the one-carbon metabolism and monoamine synthesis (Figure 2).

The methionine cycle, which is responsible for the synthesis of methionine and the universal methyl donor S-adenosylmethionine (SAM), heavily depends on vitamin B9 and B12. Methionine is produced through the methylation of homocysteine (Froese et al., 2019). This reaction is catalyzed by the methionine synthase, which uses vitamin $\mathrm{B} 12$ as a co-factor and 5-methyltetrahydrofolate (5-MTHF), a primary 
biological active form of vitamin B9 as methyl-group donor. During vitamin B9/12 deficiencies, 5-MTHF conversion to tetrahydrofolate (THF) is decreased. At the same time there is an accumulation of the metabolite homocysteine (Mikkelsen et al., 2016). Although homocysteine is an important precursor for the production of methionine, SAM, and THF, elevated concentrations of homocysteine cause cerebral damage and a decline in cognitive abilities and memory (Obeid and Herrmann, 2006; Moore et al., 2018). Being an agonist of the NMDA receptor, homocysteine can increase postsynaptic $\mathrm{Ca}^{2+}$ levels and thereby contribute to excitotoxicity (Lipton et al., 1997).

Elevated homocysteine levels can also promote oxidative stress via the production of reactive oxygen species (ROS; Djuric et al., 2018). The result is a disruption in energy supply, which can lead to neuronal damage and an increased inflammatory response (Obeid and Herrmann, 2006). Correspondingly, a vitamin B9 deficiency causes an increased expression of proinflammatory cytokines via homocysteine (Mikkelsen et al., 2017). Inflammation is affected by vitamin B9/12 via other pathways as well. The NFкB pathway is suppressed by vitamin B9 (Au-Yeung et al., 2006). Moreover, weak evidence suggests that vitamin B12 stimulates the proinflammatory interleukin-6 production in rats (Scalabrino et al., 2002).

A deficiency in vitamin B9 and B12 not only causes elevated homocysteine levels and increased inflammation in the brain, but also reduces the amount of available SAM (as measured in a reduced SAM/SAH ratio). The methyl donor SAM is required for the methylation of DNA, proteins and neurotransmitters, thereby controlling their transcription, structure and activity. Hence, abnormal SAM-levels can affect transcription, chromatin structure and DNA repair (De Berardis et al., 2016). Accordingly, $\mathrm{SAH}$ is inhibitor of methyltransferases (Berger and SassoneCorsi, 2016). Notably, there is accumulating evidence that SAM may have antidepressant effects (De Berardis et al., 2016; Karas Kuželièki, 2016). Rats fed with a diet rich in methyl-donors show improved depressive-like behaviors (McCoy et al., 2016)

Folate deficiency is associated with increased levels of DNA methyltransferases and histone methyltransferases (Ghoshal et al., 2006). Furthermore, supplementation with a variety of nutraceuticals including folate, cobalamin, choline, and Lmethionine, inhibited HDAC1 in rodents (Cho et al., 2014). Unfortunately, few studies have investigated the impact of single vitamins on chromatin marks, especially not in human peripheral tissue. An intriguing new link between the onecarbon metabolism and chromatin may be the posttranslational modification homocysteinylation, which has been detected in neurons on histone 3 lysine 79 (Zhang et al., 2018). It's relevance to mental disorders is currently not known.

Besides the one-carbon metabolism, vitamin B9 and B12 can affect monoamine synthesis. Tetrahydrobiopterin (BH4) is a major cofactor in the conversion of various amino acids to 5-HT, dopamine, and NE. Tetrahydrobiopterin is the limiting agent in the synthesis, while being also extremely susceptible to oxidation. The oxidized form of $\mathrm{BH} 4$, known as dihydrobiopterin (BH2) is reconverted into $\mathrm{BH} 4$ with the help of dihydrofolate reductase, an enzyme requiring THF as a cofactor for its reaction.
During vitamin B9 deficiency, there is lower $\mathrm{BH} 2$ recycling and monoamine production (Miller, 2008). This could result in reduced levels of 5-HT and dopamine that are often observed in MDD (Miller, 2008; Ramaekers et al., 2016).

With the help of SAM, NE is converted into melatonin, a main hormonal regulator of circadian rhythms, which is often disrupted in MDD (Mendoza, 2019). Dysregulation of the noradrenergic system due to vitamin B9/12 deficiency may therefore contribute to MDD-symptoms through a variety of mechanisms.

In summary, vitamin B9 and vitamin B12 are involved in many mechanisms that are impaired in MDD. The synthesis of monoamines, the regulation of the immune response, chromatin modifications as well as the removal of metabolic by-products with neurotoxic effects are disrupted during vitamin B9/12 deficiencies. Both interact and influence one another. This, however, also results in studies that are often insufficiently distinguishing between the effects of each vitamin on its' own.

Human studies on vitamin B9 generally support its' role in MDD. For instance, a large meta-analysis shows that vitamin B9 deficiency is associated with higher MDD risk, even after controlling for confounding factors (Gilbody et al., 2007). Vitamin B9 deficiency also occurs more often in treatmentresistant patients and correcting this deficiency can aid in MDD-treatment (Coppen and Bolander-Gouaille, 2005; Fava and Mischoulon, 2009; Mikkelsen et al., 2016). The link between vitamin B12 and Major depressive disorder is even more evident. Vitamin B12 deficiency leads to symptoms of MDD, and can be diagnosed in up to one third of MDD patients (Mikkelsen et al., 2016). Accordingly, chronic supplementation with injected vitamin B12 improved MDD-symptoms in two large cohorts (Walker et al., 2012; Syed et al., 2013). Notably, chronic supplementation with either, vitamin B9 or vitamin B12, may improve MDD-symptoms particularly in men (Murakami et al., 2008; Gougeon, 2014).

In rodents, vitamin B12 deficiency induces MDDlike symptoms (Ghosh et al., 2018). Notably, chronic supplementation with methyl donors including vitamin B9 and vitamin B12 improved depression-like behaviors in a non-deficient rodent model of early life stress (Paternain et al., 2016). Chronic vitamin B9 supplementation on its' own prevented stress-induced depressive-like effects in mice (Rosa et al., 2014). Interestingly, an acute dose of vitamin B9 was sufficient to prevent the detrimental effects of acute stress on behavior and hippocampal biomarkers of MDD in mice as well (Budni et al., 2013). Furthermore, a single acute dose of vitamin B12 in non-deficient mice ameliorated molecular and behavioral effects reminiscent of depression induced by a combination of chronic and acute stress (Trautmann et al., 2020a). This suggests, that vitamin B9 and B12 may potentially have fast-acting antidepressant effects, at least in rodents. Hence, the underlying pathways should be explored further to reveal potentially undescribed fast-acting antidepressant pathways.

Serum folate levels are reduced in patients with $\mathrm{BD}$ as well (Hsieh et al., 2019). Furthermore, BD patients may have elevated homocysteine levels during the manic episode (Permoda-Osip et al., 2013). Accordingly, it has been suggested 


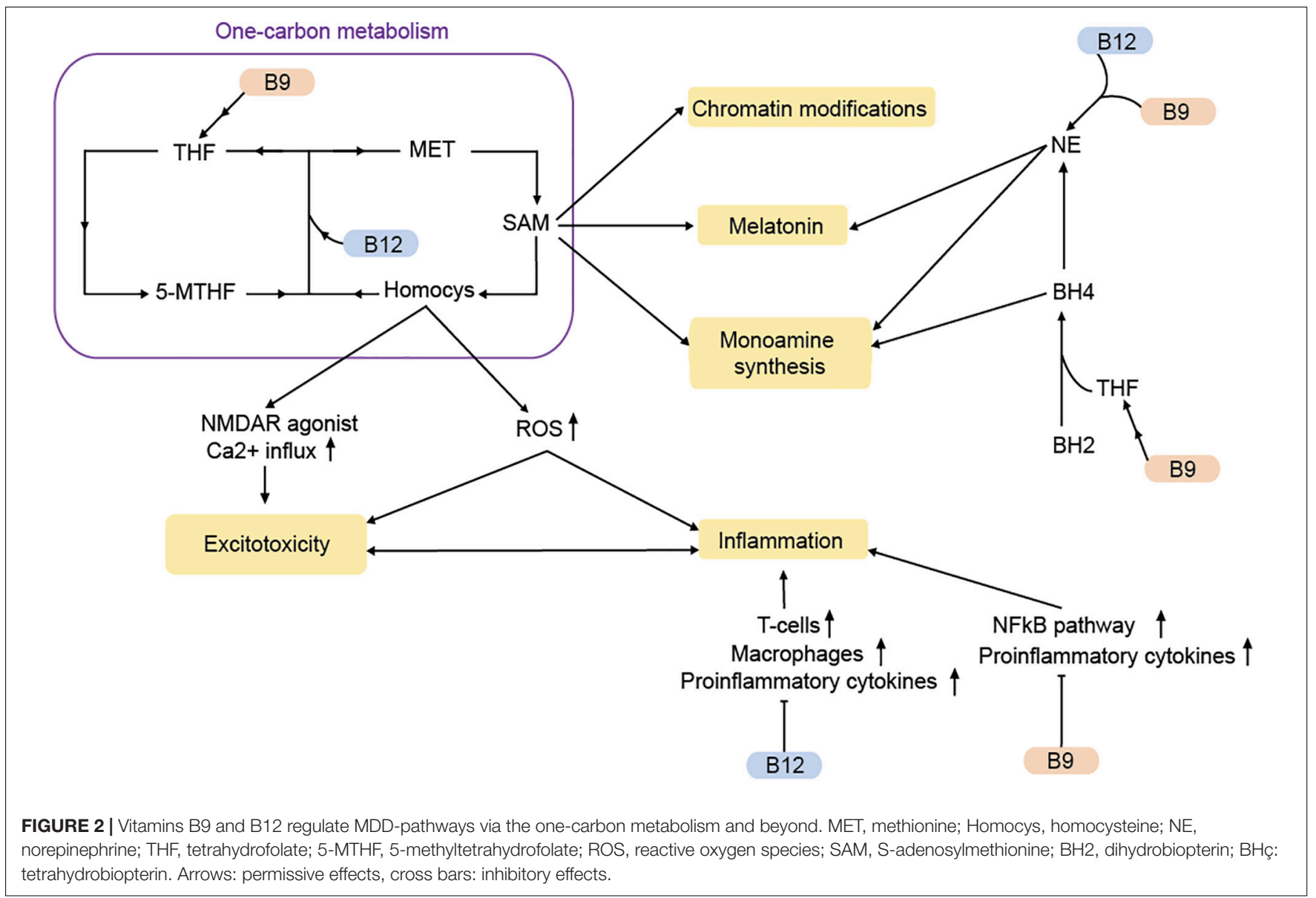

that folate as an adjunct therapy with regular medication may be beneficial to treat manic phases in $\mathrm{BD}$ patients (Behzadi et al., 2009; Nierenberg et al., 2017). In rats, too, a combination of chronic folate and lithium chloride improved behavioral measures in the metamphine model of mania (Menegas et al., 2020). However, in a prospective study with people at familial risk for mood disorders, no effect of folate on disease was observed but folate supplementation caused a slight delay in disease onset (Sharpley et al., 2014). Unfortunately, despite being otherwise rigorously designed, this study, too, did not assess any initial deficiencies. To our knowledge, no hypomania was induced by folate or vitamin B12 supplementation.

\section{TRACE MINERALS AND MDD-RISK}

\section{Magnesium May Improve Mood Through the Gut}

The bivalent cation magnesium $\left(\mathrm{Mg}^{2+}\right)$ is an important modulator of various processes in the human body. It serves as a cofactor in over 300 different reactions, including DNA replication, transcription and translation (Schwalfenberg and Genuis, 2017). Obtained from foods such as nuts, seeds, grains, and green leafy vegetables, $\mathrm{Mg}^{2+}$ is essential for healthy brain function. Accordingly, $\mathrm{Mg}^{2+}$ is implicated in a variety of illnesses (Volpe, 2013).

$\mathrm{Mg}^{2+}$ blocks the NMDAR in a voltage-dependent manner. Hence, in the brain, $\mathrm{Mg}^{2+}$ deficiency can lead to excitotoxicity and ROS production (Murck, 2013; Figure 3A). Indeed, the action of $\mathrm{Mg}^{2+}$ on the glutamatergic system has been likened to that of the glutamatergic regulator ketamine, which has fastacting antidepressant effects (Górska et al., 2019). Accordingly, both ketamine and $\mathrm{Mg}^{2+}$ evoke similar downstream changes such as increased expression of eukaryotic elongation factor 2 and BDNF (Slutsky et al., 2010; Pochwat et al., 2015), and both have similar effects on slow wave sleep in humans (Murck, 2013).

$\mathrm{Mg}^{2+}$ deficiency also acts on the brain indirectly via the gut-brain-axis. The gut microbiome produces hormones and neuro-active molecules and has a major impact on the immune system. Notably, there is an interplay between microbiome composition and MDD (Bastiaanssen et al., 2020). $\mathrm{Mg}^{2+}$ deficiency disturbs the composition of the gut microbiome in mice (Pyndt Jørgensen et al., 2015), while $\mathrm{Mg}^{2+}$ supplementation increases the microbial diversity in the gut (Crowley et al., 2018). $\mathrm{Mg}^{2+}$ induced changes in the microbiome can also affect the levels of circulating cytokines, and therefore increase the risk for systemic inflammation during $\mathrm{Mg}^{2+}$ deficiency (Wang et al., 2018). An increase in 
the inflammatory markers C-reactive protein (CRP), IL-6, and $\mathrm{TNF} \alpha$ can contribute to neuronal damage and defective myelination, and may contribute to the cognitive symptoms in some depressed patients (Cubała and Landowski, 2014). Since glutamate-induced ROS can trigger an immune response as well, $\mathrm{Mg}^{2+}$ deficiency can alter the immune response by two different mechanisms.

However, not only the immune response is modified by $\mathrm{Mg}^{2+}$, but also the stress response (Figure 3B). $\mathrm{Mg}^{2+}$ controls the HPA axis by reducing the release of adrenocorticotropic hormone (ACTH) as well as modulating the sensitivity to it (Wang et al., 2018). As a result, $\mathrm{Mg}^{2+}$ may prevent the hyperactivation of the HPA axis often seen in MDD-patients.

$\mathrm{Mg}^{2+}$ plays a role in enzymatic reactions that mediate the maintenance of DNA structure. In particular, the role in maintaining telomere integrity is well described. Here, $\mathrm{Mg}^{2+}$ appears to be particularly necessary to maintain Lamin $B$ interaction with the chromatin (Maguire et al., 2018). Furthermore, $\mathrm{Mg}^{2+}$ may indirectly increase the risk of mtDNA damage by being required for a proper energy metabolism in mitochondria (Zheltova et al., 2016; Maguire et al., 2018).

In rodent studies, $\mathrm{Mg}^{2+}$ deficiency induces depressive-like behaviors (Singewald et al., 2004; Spasov et al., 2008), while co-administration of $\mathrm{Mg}^{2+}$ potentiates the beneficial effects of common antidepressants (Poleszak et al., 2007). In human studies, there is some evidence for $\mathrm{Mg}^{2+}$ deficiency occurring more commonly in MDD patients. However, the effects are heterogeneous (Serefko et al., 2013; Yary et al., 2016; Wang et al., 2018; Górska et al., 2019; Sun et al., 2019; Tarleton et al., 2019). On the other hand, chronic $\mathrm{Mg}^{2+}$ supplementation appears to improve MDD symptoms even without a prior diagnosis of $\mathrm{Mg}^{2+}$ deficiency (Tarleton et al., 2017). Intriguingly, improvements may occur much more rapidly than with traditional antidepressant treatment (Eby and Eby, 2006).

While $\mathrm{Mg}^{2+}$ supplementation appears to have antidepressive effects, at least in rodents and certain human populations, high doses of $\mathrm{Mg}^{2+}$ supplements can have a variety of side effects, so careful assessment of an underlying $\mathrm{Mg}^{2+}$ deficiency and proper dosing are key (Van Laecke, 2019).

\section{The Immunomodulating Mineral Zinc}

The second most common trace element in the human body after $\mathrm{Mg}^{2+}$ is zinc $\left(\mathrm{Zn}^{2+}\right)$. Although $\mathrm{Zn}^{2+}$ can be obtained from plant foods including cereals and legumes, the absorption of the ion can be impaired by the phytic acid present in plants. The bioavailability of $\mathrm{Zn}^{2+}$ from crops is therefore often limited (Gibson et al., 2010). The main sources of $\mathrm{Zn}^{2+}$ are thus red meat, oysters and crabs. $\mathrm{Zn}^{2+}$ is involved in countless enzymatic reactions, both systemically and in the brain (Takeda, 2000). These include pathways that regulate biosynthesis, neurogenesis, antioxidant defense and the immune response (Szewczyk et al., 2011; Wang et al., 2018; Prasad and Bao, 2019).

Intriguingly, there is a strong negative association between MDD and $\mathrm{Zn}^{2+}$ levels, which has led to the suggestion to use serum $\mathrm{Zn}^{2+}$ levels as a biomarker for affective disorders (Maes et al., 1994; Szewczyk et al., 2011; Siwek et al., 2013;
Wang et al., 2018). Correspondingly, $\mathrm{Zn}^{2+}$ supplementation generally improves MDD symptoms (Wang et al., 2018) and co-treatment with $\mathrm{Zn}^{2+}$ improved antidepressant action in two placebo controlled double-bind studies (Nowak et al., 2003a; Siwek et al., 2010). In various rodent models of depression, both chronic and acute $\mathrm{Zn}^{2+}$ supplementation improved depressionlike behaviors (Kroczka et al., 2000; Nowak et al., 2003b; Cieślik et al., 2007; Sowa-Kuæma et al., 2008; Wang et al., 2018) and promoted the effects of antidepressants in these models (Szewczyk et al., 2011). It is still unclear how exactly $\mathrm{Zn}^{2+}$ is involved in the clinical picture of MDD. However, there is a plethora of hypotheses:

$\mathrm{Zn}^{2+}$ is enriched in glutamatergic presynaptic vesicles in the central nervous system (Frederickson et al., 2000). Being an antagonist of the NMDA receptor (Peters et al., 1987) $\mathrm{Zn}^{2+}$ may help to reduce excitotoxicity (Figure 3). $\mathrm{Zn}^{2+}$ also may have antioxidant effects by inhibiting the enzyme NADPH oxidase, which is responsible for the production of ROS, and generates proteins that act as scavengers for free radicals (Doboszewska et al., 2016). Therefore, $\mathrm{Zn}^{2+}$ deficiency results in a greater production of ROS, and increased levels of QUIN. As a result, QUIN as NMDA agonist increases excitotoxicity while at the same time, less TRP is available for 5-HT production (Doboszewska et al., 2016). $\mathrm{Zn}^{2+}$ can also counteract the neurotoxicity caused by chronic inflammation via the NFк B-pathway.

A20, a zinc-finger containing protein, is an endogenous inhibitor of the NFKB-pathway. $\mathrm{Zn}^{2+}$ leads to an increased production of the A20 and thereby suppresses the formation of pro-inflammatory cytokines (Hongxia et al., 2019). This suggests that $\mathrm{Zn}^{2+}$ affects inflammation and oxidative stress in various ways and thus serves as an important regulator of pathways that are known to contribute to MDD.

$\mathrm{Zn}^{2+}$ is also involved in the regulation of neuropeptide Y (NPY) (Lee et al., 1998; Levenson, 2003). Neuropeptide $\mathrm{Y}$ is released from nerve endings in various regions of the brain, including the hypothalamus, cortex, amygdala, and hippocampus, some of which are associated with MDD. Both, $\mathrm{Zn}^{2+}$ and NPY regulate daily food intake (Levenson, 2003), may be of interest in the context of anhedonia as a symptom of MDD as well as co-morbid illnesses such as eating disorders (Shay and Mangian, 2000). Furthermore, NPY controls sleep and is particularly involved in promoting and modulating the REM sleep phase (Dyzma et al., 2010). However, probably the most important aspect linking NPY to MDD is the peptide's involvement in maintaining the homeostasis of the HPA axis. In the hypothalamus, NPY antagonizes corticotropin-releasing hormone, which normally coordinates the release of ACTH from the pituitary gland (Thorsell, 2010). Therefore, NPY can indirectly inhibit ACTH. Adrenocorticotropic hormone release follows a circadian rhythm and helps prevent the hyperactivation of the HPA axis (Heilig, 2004; Adam and Epel, 2007; Morales-Medina et al., 2010).

Altered levels of NPY and its receptors have been reported in the context of MDD and stress (Morales-Medina et al., 2010). In rodent models, $\mathrm{Zn}^{2+}$ deficiency prevents the release of NPY and thus may cause a dysregulation of various physiological 


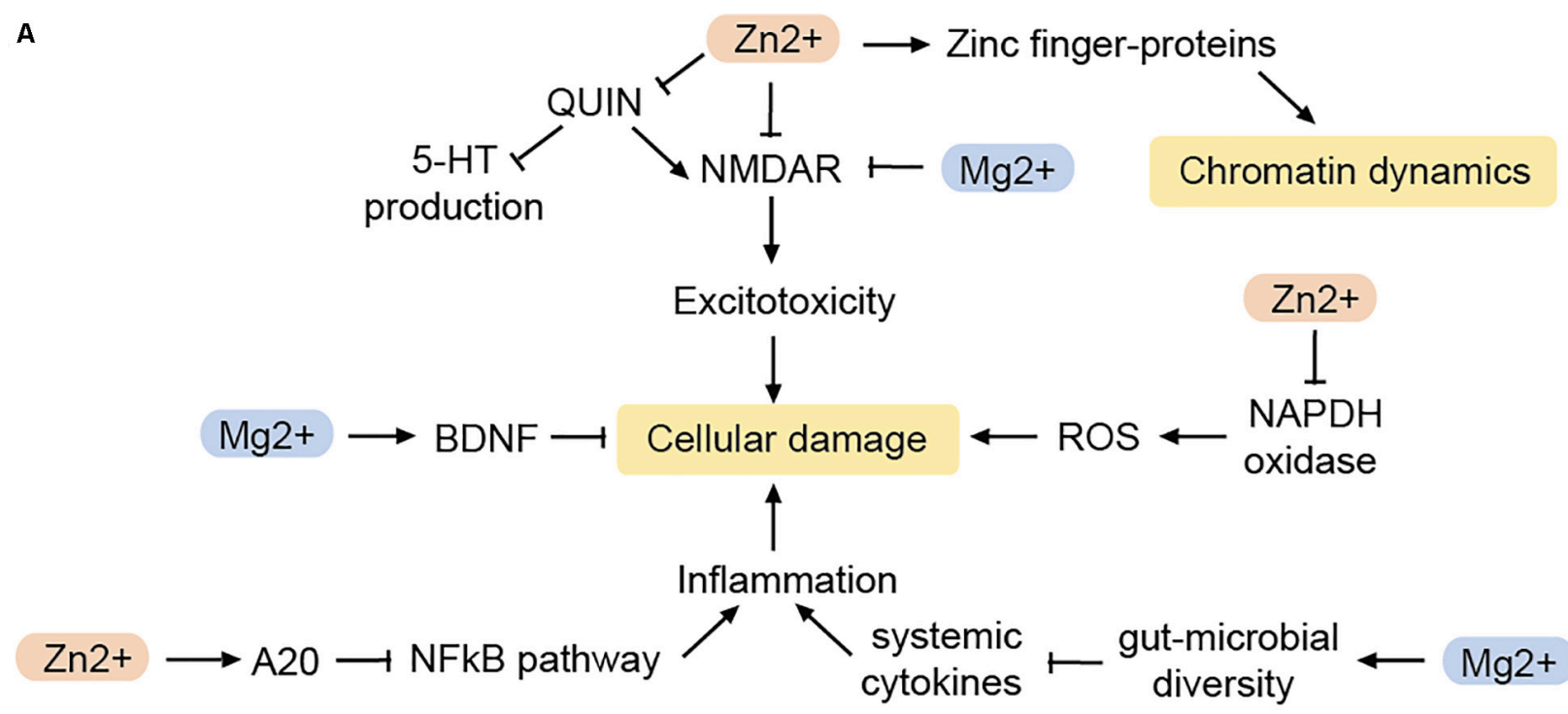

B

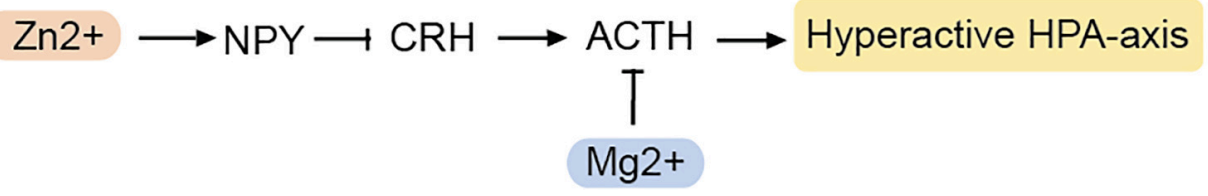

FIGURE 3 | Impact of zinc and magnesium on MDD-related pathways. (A) Pathways reducing cellular damage. (B) Pathways that inhibit a hyperactive HPA-axis. BDNF, brain-derived neurotrophic factor; NPY, neuropeptide Y; CRH, corticotropin-releasing hormone; ACTH, adenocorticotropic hormone; QUIN, quinolonic acid; ROS, reactive oxygen species. Arrows: permissive effects, cross bars: inhibitory effects.

functions, including feeding behaviors and the stress response (Levenson, 2003; Reichmann and Holzer, 2016).

$\mathrm{Zn}^{2+}$ may also indirectly act as a neuromodulator, although its function in this respect is still poorly understood. $\mathrm{Zn}^{2+}$ can be stored in synaptic vesicles and may help facilitate GABA-ergic neurotransmission (Minami et al., 2002). $\mathrm{Zn}^{2+}$ can also interact with ZnR/GPR39, a G-protein coupled receptor (Hershfinkel, 2018). Interestingly, ZnR/GPR39 is downregulated in $\mathrm{MDD}$ and upregulated by antidepressant treatment (Młyniec et al., 2015). Furthermore, in mice the zinc receptor agonist TC-G 1008 reduces the immobility time in the forced swim test (Starowicz et al., 2019). Activation of ZnR/GPR39 triggers a variety of biochemical pathways associated with cell proliferation, anti-apoptotic properties and neuroplasticity (Hershfinkel, 2018). These include the ERK/MAPK signaling pathway (Holst et al., 2007), the AKT/PI3K signaling pathway (Dong et al., 2016) and the CREB/BDNF pathway (Mlyniec et al., 2015). Hence, $\mathrm{ZnR} / \mathrm{GPR} 39$ is involved in various mechanisms that are dysregulated in MDD, making it an interesting potential therapeutic target for MDD.

$\mathrm{Zn}^{2+}$ is a cofactor for histone deacetylases, the enzymes which remove acetyl groups from histones (Seto and Yoshida, 2014). Some of these, including HDAC2 and SIRT1, are implicated in MDD (Lu et al., 2018; Penner-Goeke and Binder, 2019).
Additionally, protein binding to the DNA is faciliated by a so called zinc finger-domain. Accordingly, zinc finger proteins regulate chromatin on a variety of levels (Klug, 2010). They include transcription factors as well as the structural factor CTCF (Phillips and Corces, 2009). Hence, a $\mathrm{Zn}^{2+}$ deficiency is likely to fundamentally disturb chromatin dynamics and in consequence transcription.

Taken together, $\mathrm{Zn}^{2+}$ may impact on $\mathrm{MDD}$ via direct and indirect mechanisms. Correcting $\mathrm{Zn}^{2+}$ deficiencies may improve MDD-symptoms and amplify the effects of antidepressant treatment. Studies on the molecular basis of $\mathrm{Zn}^{2+}$ action have revealed a bouquet of previously unknown neural pathways and mechanisms. However, $\mathrm{Zn}^{2+}$ should only be taken in physiological quantities as overdosing can induce a variety of side effects including neurotoxicity (Salzman et al., 2002; Yang et al., 2013).

\section{NEUROPROTECTION VIA FATTY ACIDS - OMEGA-3 AND OMEGA-6}

The organ with the highest proportion of fatty acids, besides adipose tissue itself, is the brain (Sastry, 1985). Fatty acids are essential for the development and maintenance of the central nervous system, are involved in various biological 
processes within the brain and play an important role in the stability and structure of membranes (Rao et al., 2008). Of all lipids found in the brain, poly-unsaturated fatty acids (PUFAs) constitute the largest fraction (Sastry, 1985). In this context,

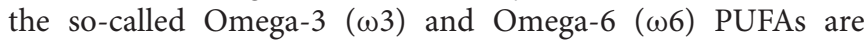
of great importance. Members of these two groups cannot be synthesized by the body and must therefore be provided by the diet (Simopoulos, 1991; Gibson and Makrides, 2001). The short-chain precursors of $\omega 3$ ( $\alpha$-linoleic acid, ALA) and $\omega 6$ PUFAs (linoleic acid, LA) can be obtained from fish, cereals, vegetables or cereal oil. ALA and LA are further converted into docosahexaenoic acid (DHA), eicosapentaenoic acid (EPA), and arachidonic acid (AA), generating the three main long chain PUFAs present in the brain (Thomas Larrieu and Layé, 2018). Here, they serve as signal molecules and are involved in the regulation of membrane fluidity and function, inflammation, the HPA axis and neurogenesis. As soon as the long-chain $\omega 3$ and $\omega 6$ PUFAs are transported into the brain, the fatty acids are esterified at and attached to neuronal and glial cell membranes (Layé et al., 2018). Through the activation of glutamatergic, serotonergic, cholinergic, or dopaminergic receptors, or through inflammation, PUFAs can be released from the cell membrane (Bazinet and Layé, 2014). In their detached forms, they can act on a variety of receptors, including the G-protein coupled receptor GPR32 and the peroxisome proliferator-activated receptor $\gamma(\operatorname{PPAR} \gamma)$ (Bazinet and Layé, 2014; Marion-Letellier et al., 2016). Peroxisome proliferatoractivated receptor agonists have neuroprotective and antiinflammatory properties (Kapadia et al., 2008) and have been suggested for the treatment of MDD (Colle et al., 2017). Furthermore, $\omega 3$ and $\omega 6$ PUFAs themselves display antioxidative effects and, when metabolized to oxylipins, they are involved in modulating the immune response as well as the activity of the HPA axis (Bazinet and Layé, 2014; Layé et al., 2018).

DHA interacts with retinoid X receptors (RXR; Calderon and Kim, 2007) and the beneficial effects of DHA on measures despair are blocked in RXR knockout-mice (Wietrzych-Schindler et al., 2011). Similarly, inhibition or ablation of the DHA receptor GPR40 (Figure 4) is linked to effects of chronic stress and depressionlike states in mouse models (Nishinaka et al., 2014; Aizawa et al., 2017, 2018). Additionally, GPR40 regulates BDNF levels in mice (Sona et al., 2018) and primates (Boneva and Yamashima, 2012).

Furthermore, DHA and its metabolite EPA are used for the production of the factors resolvin and neuroprotectin (Bazinet and Layé, 2014). These proteins inhibit the infiltration of immune cells into the brain, the production of inflammatory modulators and they initiate the restoration of damaged neurons (Layé et al., 2018). Therefore, $\omega 3$ PUFAs potentially have antiinflammatory and neuroprotective properties. Furthermore, they have antioxidant properties: ROS can be regulated by EPA and DHA via the nuclear factor-like 2 (NRF2) antioxidant pathway (Bang et al., 2017; Zgórzyńska et al., 2017).

Heavy research has been undertaken to investigate the link between $\omega 3$ PUFAs and MDD. There appears to be an inverse relationship between the intake of food rich in $\omega 3$ PUFAs and MDD, although the variability between studies warrants more investigation (Grosso et al., 2014; Larrieu and Layé, 2018). For instance, depression rates are generally higher in regions with low fish consumption, a main source of $\omega 3$ PUFAs (Grosso et al., 2014). Accordingly, supplementation with $\omega 3$ PUFAs may improve MDD-symptoms (Bozzatello et al., 2016; Trebaticka et al., 2020). $\omega 3$ PUFAs also appear to improve markers associated with MDD in humans including the HPA axis (Mocking et al., 2013; Thesing et al., 2018) and inflammatory markers (Layé et al., 2018).

In $\omega 3$ PUFA deficient rodents, hyperactivity of the HPA axis was observed as well (Morgese et al., 2017; Tang et al., 2018). Conversely, $\omega 3$ PUFA supplementation ameliorated behavioral deficits induced by stress in rodent models (Song et al., 2003; Ferraz et al., 2011). In addition, accumulating evidence suggests that in rodents chronic stress-induced depressive-like behaviors and stress-induced molecular alterations in the HPA axis, antioxidant pathways and the gut microbiome may be ameliorated by $\omega 3$ supplementation (Larrieu et al., 2014; Pusceddu et al., 2015; Wu et al., 2016; Réus et al., 2018).

Poly-unsaturated fatty acids can regulate chromatin dynamics. For instance, they are ligands to PPARs, which regulate gene expression, chromatin structure, and chromatin modifying enzymes (Yu and Reddy, 2007; Romagnolo et al., 2014). Accordingly, maternal separation and unpredictable maternal stress (MSUS) stimulates ALA/LA and (AA pathways in adult mice (van Steenwyk et al., 2020). The resulting inhibition of PPARs can affect transposable elements and gene expression. These effects may contribute to intergenerational transmission of certain stress-induced disease risks (van Steenwyk et al., 2020). Effects of various PUFA on DNAme have been described as well (KiecWilk et al., 2011; Kulkarni et al., 2011). Various human studies suggest epigenetic effects of PUFAs, too. Mostly these studies supplement with a combination of several PUFAs and are not controlled for confounding factors (González-Becerra et al., 2019).

Interestingly, butyric acid, a short fatty acid produced by the microbiome from dairy products, can inhibit HDACs (Lee et al., 2017; González-Becerra et al., 2019). The derivative sodium butyrate is promoted for treating mood disorders and cognitive deficits (Stilling et al., 2016).

Mixed results were observed in BD patients when dietary PUFA-supplements were administered or in correlative studies with systemically circulating PUFAs (Saunders et al., 2016). Supplementation with omega-3 may improve BD symptoms (Sarris et al., 2012). However, in BD patients, AA metabolism may be increased as shown by postmortem studies (Kim et al., 2011) and by circulating AA plasma levels (Sublette et al., 2007). Furthermore, medication for BD may reduce the AA cascade (Rapoport, 2014). Consistently, an upregulation of the AA cascade, e.g., via supplements, may worsen the illness (Saunders et al., 2016). Hence, the type of PUFA supplement will be crucial for treatment outcome. Accordingly, an imbalance between 


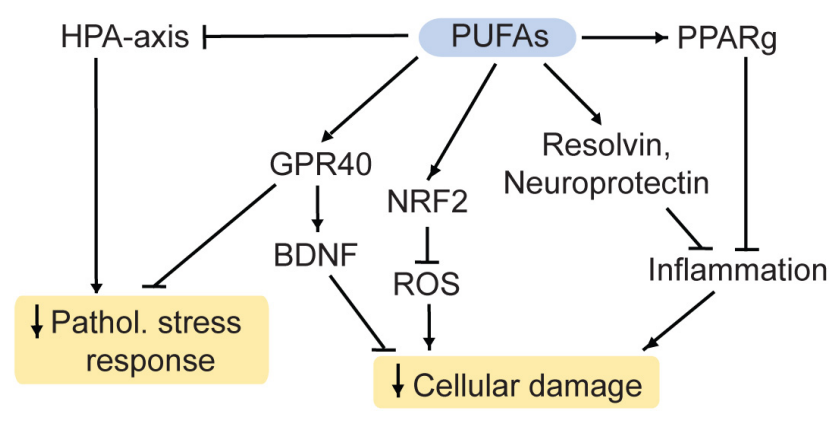

FIGURE 4 | PUFAs reduce cellular damage and the pathological stress response. HPA, hypothalamic-pituitary-adrenal; PUFA, polyunsaturated fatty acid; ROS, reactive oxygen species; Pathol., pathological; PPARg, Proliferator-activated receptor gamma; NRF2, nuclear factor-like 2. Arrows: permissive effects, cross bars: inhibitory effects.

$\omega 3$ and $\omega 6$ PUFAs is often associated with depression, perhaps through an increased inflammatory response (Trebaticka et al., 2020).

Taken together, there is increasing consent that $\omega 3$ PUFA supplementation promotes positive outcomes for mental health problems including MDD. Combined with other benefits such as a lower risk for cardiovascular disease, high $\omega 3$ PUFA content in the diet is likely to generally improve health in human populations. However, supplementation may have to be tailored to the type of depression (MDD/BD) as well as to the antidepressant treatment that is currently being taken by the patient.

\section{CAFFEINE'S UNDEREXPLORED MOOD-ELEVATING PROPERTIES}

All previously mentioned dietary factors are essential for proper functioning of the human body. Vitamins, minerals and fatty acids are obtained through diet and a deficit contributes to the development of various diseases, including MDD. Treating an underlying deficiency in these factors may help to reduce MDD-symptoms and there is preliminary evidence that some of these dietary factors may have antidepressant properties even in non-deficient populations. However, there are also non-essential dietary factors that can aid in the treatment of MDD. This includes caffeine, the most frequently consumed psychoactive substance in the world (Ferré, 2013).

The main molecular targets of caffeine are G-protein coupled adenosine receptors (A1, A2A, A2B, A3) (Ribeiro and Sebastio, 2010). Purinergic signaling has been generally associated with mood disorders (van Calker et al., 2019). At a first glance, adenosine receptors seem to regulate a complex web of pathways due to the fact that some receptor types have opposing functions. While the stimulation of A2AR increases symptoms associated with depression, A1R can promote rapid antidepressant effects (van Calker et al., 2019). This may be due to the fundamental classification of receptor types as A1R inhibiting cyclic adenosine monophosphate

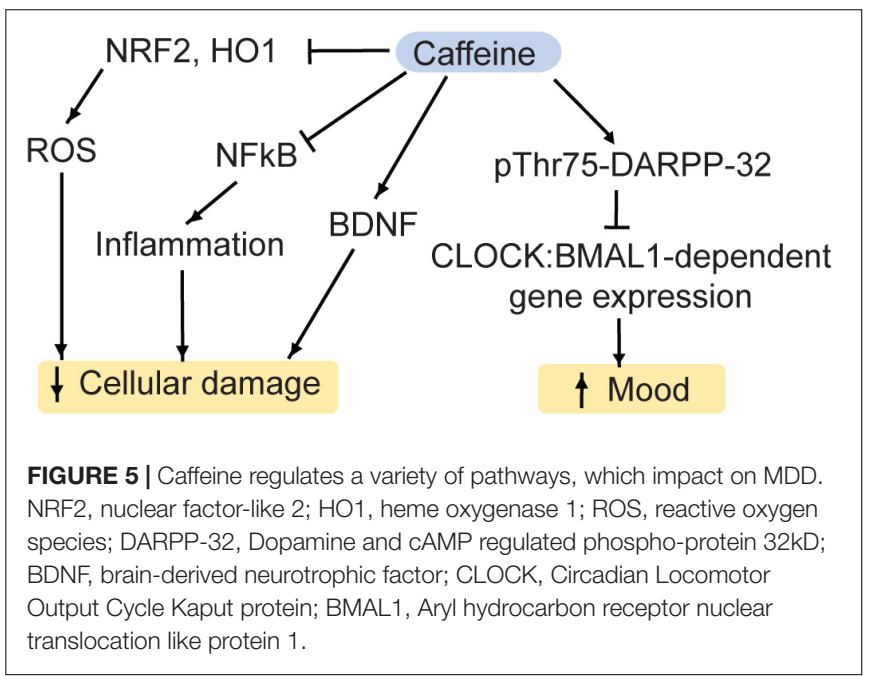

accumulation and subsequent activation of protein kinase A, and A2R stimulating it (van Calker et al., 1979, 1978). Among $\mathrm{A} 2 \mathrm{R}$, the A2AR has the highest affinity for adenosine (van Calker et al., 2019). In addition to regulating proteinase $\mathrm{K}$ activity, binding of adenosine to A1R inhibits the release of glutamate from the pre-synapse and reduces the postsynaptic excitability via potassium channels (van Calker et al., 2019). Furthermore, the activity of the A1R can be inhibited by the A2AR (Cunha et al., 1994), and the A2AR can interact with dopamine 2-receptors (Fuxe et al., 2007). This interplay makes it difficult to predict outcomes of purinergic stimulation or inhibition with pharmacological compounds such as caffeine on a receptor level. However, there is an integration of pathways downstream of protein kinase $\mathrm{A}$, which integrates purinergic as well as glutamatergic and dopaminergic signaling: cAMP-regulated phosphoprotein $\mathrm{Mr} 32000$ (DARPP-32) is a key signaling protein in the brain reward system, upon which a variety of signal transduction pathways converge (Yger and Girault, 2011; Figure 5). We recently showed that in mouse striatum, acute caffeine administration can ameliorate mood via the DARPP-32: Circadian Locomotor Output Cycle Kaput protein (CLOCK) pathway (Trautmann 
et al., 2020b). Specifically, caffeine increases the phosphorylation of Thr75 on DARPP-32 (Lindskog et al., 2002). Thr75 is necessary for DARPP-32 binding to CLOCK, a main regulator of circadian rhythms, which is implicated in mood disorders as well (McClung, 2007b,a). Importantly, DARPP32 has been linked to mood disorders as well (Kunii et al., 2014). Mutation of Thr75 to alanine (T75A) inhibits DARPP32 binding to CLOCK. Importantly, it also prevents the mood-elevating effects of caffeine, which occur in a diurnal manner (Trautmann et al., 2020b). Since caffeine affects CLOCK: Aryl hydrocarbon receptor nuclear translocationlike protein 1 (BMAL1) binding to chromatin, the caffeineinduced behavioral changes are likely mediated by gene expression changes, with the affected the gene products currently under investigation. Not only do CLOCK and BMAL1 influence the sleep-wake cycle and various circadian physiological functions (e.g., body temperature), but they also regulate the release of glucocorticoids (Landgraf et al., 2014; Mendoza, 2019). In turn, many CLOCK-regulated genes possess glucocorticoid responsive elements within their promoter regions (Kiessling et al., 2010; Landgraf et al., 2014). Hence, the caffeine-DARPP-32:CLOCK pathway may interact with stressinduced pathways as well, however this subject, too, is still under investigation.

Caffeine may also affect antidepressant-associated pathways independently of DARPP-32. For instance, in mouse hippocampus, acute caffeine can stimulate BDNF expression via the A1R-cAMP-CREB-BDNF pathway (Connolly and Kingsbury, 2010) or via the insulin receptor substrate 2 (IRS2)-phosphoinositide 3 kinase (PI3K)-Akt-pathway (Lao-Peregrín et al., 2017).

Moreover, acute treatment with caffeine reduces oxidative stress in rodents. Specifically, caffeine inhibits the markers of oxidative stress NRF2 and heme oxygenase 1 (HO-1), the proinflammatory cytokine $\mathrm{NF \kappa B}$ as well as pro-apoptotic pathways (Hall et al., 2015; Endesfelder et al., 2017).

Human cross-sectional and prospective studies generally observed an inverse relationship between coffee intake and MDD-risk (Hall et al., 2015). Given various other bioactive compounds in coffee other than caffeine, these studies are by nature not conclusive about caffeine effects alone. To pinpoint the effects of caffeine, de-caffeinated coffee may be used as a control. In humans, the beneficial effects of caffeine occur at appropriate quantities (4-7 cups a day). However, a higher intake may actually impair mental health (Hall et al., 2015). In rodent models of depression, chronic caffeine improved motivational and cognitive deficits (Machado et al., 2020) as well as escape behaviors and measures of anxiety (Pechlivanova et al., 2012). Furthermore, chronic caffeine administration increased the resilience to chronic stress in rodents (Yin et al., 2015). While caffeine also appears to have fast-acting benefits on mood (Trautmann et al., 2020b) and synaptic plasticity of the brain reward system (Engmann et al., 2016), acute effects of caffeine need to be explored in further detail.

Besides caffeine, caffeinated beverages can contain other active substances, such as the nonselective phosphodiesterase and histone deacetylase-2 inhibitor theophylline (Barnes, 2013). In order to rule secondary effects due to these compounds, in human studies, caffeinated beverages should be directly compared with their decaffeinated counterparts or dissolved caffeine should be utilized.

In summary, caffeine appears to have several neuroprotective effects and may rapidly improve mood. However, studies using chronic and acute doses of caffeine are often difficult to compare. The psychostimulant effects of acute caffeine can impact on the interpretation of behavioral results gained after acute caffeine administration. Notably, the effects of acute caffeine are light-phase dependent in mice (caffeine improves mood only in the active phase), which needs to be taken into consideration for future investigations in rodents. The few human studies on the subject are difficult to interpret, perhaps because of the high baseline consumption of caffeine in the human population or due to other bioactive compounds in caffeinated beverages. Furthermore, there may an optimal dose of caffeine intake as well as common side effects such as high blood pressure. A variety of studies have described anxiogenic effects of caffeine under certain conditions (Charney et al., 1985; Bhattacharya et al., 1997). Nevertheless, the available research suggests that acute caffeine intake may rapidly improve mood and that caffeine may be a valuable research tool to potentially identify previously unknown antidepressant pathways.

\section{CONCLUSION - NUTRITION AN DEPRESSION: RESEARCHERS STILL HAVE A LOT ON THEIR PLATE}

Major depressive disorder is one of the most common mental illnesses worldwide. It is disabling not only to patients and their loved ones but represents a major economical burden to societies as well. Although there are various treatment options available, these often take weeks to fully function. In some patient cohorts, current antidepressants are not affective at all. For instance, in the $\mathrm{STAR}^{*} \mathrm{D}$ trial, a major longitudinal study measuring antidepressant efficiency in more than 4,000 outpatients, the response rate to a 14-week treatement with selective 5-HT reuptake inhibitors was only $47 \%$ (Warden et al., 2007). It is therefore of great interest to find new approaches to treat or even help prevent MDD. In this review, we have discussed examples of dietary factors, which can assist in the therapy of MDD. These include essential nutrients such as B vitamins (B6, B9, B12), minerals $\left(\mathrm{Zn}^{2+}\right.$, $\mathrm{Mg}^{2+}$ ) and PUFAs, which are frequently deficient in MDDpatients. Indeed, MDD may be a symptom of many dietary deficiencies. Hence, rectifying the diet can improve symptoms associated with monoamine signaling transmission, neural inflammation, HPA axis hyperactivity and oxidative stress. However, most research questions on this subject are still insufficiently addressed: Can chronic or acute supplementation of those dietary factors improve MDD-symptoms even in non-deficient patient populations? What are the underlying pathways beyond traditional hypotheses of MDD? In order to 
address these gaps in the field, mouse models of depression, such as the CVS-model (Labonte et al., 2017) should be chronically or acutely supplemented with various dietary factors and behavioral testing should be applied to observe behavioral improvements. Besides classical tests that address mood and anhedonia, circadian alterations need to be considered as well, since they are a substantial factor of MDD-symptomology. RNAsequencing should be performed as an unbiased approach to identify altered gene products. Notably, research on animal models should be performed in their active phase, since acute behavioral effects can be masked by artificially measuring behavioral changes at a time, when mice are typically asleep (Trautmann et al., 2020b).

Caffeine has shown beneficial effects on mood in mice as well. As with the other dietary factors, effects of acute administration in human MDD-cohorts have been insufficiently documented. Given that dietary factors and caffeine are safe to administer, these studies should be feasible in the future. Special attention needs to be paid to separate patient cohorts that are regularly using vitamin supplements/caffeine and to take into consideration that this may introduce behavioral biases as well. Furthermore, studies should clearly state whether patients suffer from a nutritional deficiency before starting supplementation. Supplying nutrients beyond physiological requirements may have consequences distinct from a rescue of nutrient deficiency. Moreover, the timing of supplementation may be relevant. Data from animal studies suggest that certain interventions may reverse chronic stress effects with a supplementation at the end of the stressor. This may reflect best a scenario, when conventional rapidacting antidepressant drugs are administered as well (Bagot et al., 2017). However, preventative measures may be a more sustainable approach to mental illness. Hence, the timing of supplementation, together with the assessment of the deficiency state of patients for multiple nutrients, should be a priority in future experiments. Furthermore, confounding factors present in many studies may lead to nutritional deficiencies and increased MDD risk as well. These include certain life style choices such recreational drug intake, a lack of exercise or unhealthy eating habits may both. Future studies would have to control for those factors. Ideally, prospective studies randomly assign patients to placebo vs. supplement groups and measure MDD outcome in the future. This would allow for causal instead of purely correlative evidence. Experimenters should, however, assess deficiency levels in the beginning of the study. Unfortunately this has not been done in many previous prospective studies.

Another aspect that needs to be taken into consideration is a reduction of both, nutritional deficiencies and MDD symptoms by tertiary interventions such as antidepressants, exercise or psychotherapy. Furthermore, deficiencies may represent adaptive responses to risk factors for MDD such as inflammation and oxidative stress. However, independently of the cause of comorbid deficiencies, a rescue of MDD symptoms through supplementation remains intriguing. When studying the effects of supplements in patient cohorts, pharmacological interactions between supplements and medication (such as selective 5-HT reuptake inhibitors) may have to be taken into consideration.

When orally administered, supplements are likely to have a variety of systemic effects, all of which are insufficiently explored. For instance, they may affect the microbiome, liver metabolism or the HPA axis. Hence, brain physiology may be affected directly as well as indirectly. Approaches such as oral administration vs. i.p.-injection and microinfusion of supplements into various brain areas in MDD-mouse models will help to untangle the underlying mechanisms.

As several supplements converge onto the same pathways (inflammation, HPA-axis, DNA methylation), a variety of supplements may induce similar outcomes. This makes an interpretation of deficiencies more challenging, as a combination of deficiencies would have to be assessed. Equally, a combination of supplements may provide a similar, albeit unspecific, outcome, which may improve allover mental health. All these factors make studies on dietary factors in mental illness a complex undertaking.

This complexity is increased by the fact that dietary factors are unlikely to have specific effects for MDD. Instead, they may alter the risk for other mental illnesses such as BD and schizophrenia as well (Moustafa et al., 2014; Bozzatello et al., 2016; Ashton et al., 2019). We are not aware of supplements that benefit MDD while aggravating symptoms of mania or schizophrenia. Instead it is likely that certain dietary factors alter endophenotypes that are relevant to a spectrum of mental illnesses. For instance, DNA methylation is affected in MDD, but also in drug addiction (Brown and Feng, 2017) and Alzheimer's disease (Qazi et al., 2018). Hence, altering the one-carbon metabolism through vitamins B9 and B12 may change the symptomology for all of these conditions. Accordingly, the relevance of dietary factors may have to be studied in the context of certain endophenotypes such as cognitive abilities, social interaction or psychosis, rather than the combination of symptoms that is known as MDD.

Ideally, personalized nutritional interventions would be adapted to other occurring stressors in patients' lives. Based on currently available data, reversal or prevention of stress effects may benefit those patients most, which have been exposed to stress recently. In contrast, studies on nutrients' effects on early life stress-induced symptoms are more sparse. Additionally, the interaction of nutrients with genetic components or environmental risk factors for MDD other than stress are largely unexplored as well.

Basic research on animals may identify more potent molecular targets regulated by dietary factors, which may ultimately be used to develop faster acting antidepressant drugs, which circumvent the side effects of currently available medications.

In this review, we have only discussed a few selected dietary factors. There are many other dietary compounds that have not been included in this review but may still have an effect on MDD. Vitamins B2 (riboflavin) and B3 
(nicotinic acid) are highly relevant to metabolism as they are essential for the synthesis of flavin adenine dinucleotide (FAD) and nicotineamide adenine dinucleotide (NAD), respectively. NAD and FAD are not only key parts of the energy metabolism but they also participate in chromatin regulation (Berger and Sassone-Corsi, 2016).

Furthermore, the combination and timing of certain diets, such as ketogenic diet or intermittent fasting were not discussed here. Altogether, the field of nutrition research in psychiatry, while gaining more momentum in recent years, is still in its infancy.

\section{REFERENCES}

Adam, T. C., and Epel, E. S. (2007). Stress, eating and the reward system. Physiol. Behav. 91, 449-458. doi: 10.1016/j.physbeh.2007. 04.011

Aizawa, F., Nakamoto, K., and Tokuyama, S. (2018). The involvement of free fatty acid-GPR40/FFAR1 signaling in chronic social defeat stress-induced pain prolongation in C57BL/6J male mice. Psychopharmacology 235, 2335-2347. doi: 10.1007/s00213-018-4930-8

Aizawa, F., Ogaki, Y., Kyoya, N., Nishinaka, T., Nakamoto, K., Kurihara, T., et al. (2017). The deletion of GPR40/FFAR1 signaling damages maternal care and emotional function in female mice. Biol. Pharm. Bull. 40, 1255-1259. doi: 10.1248/bpb.b17-00082

Andrade, C. (2017). Ketamine for depression, 1: clinical summary of issues related to efficacy, adverse effects, and mechanism of action. J. Clin. Psychiatry 78, e415-e419.

Anthes, E. (2014). Depression: a change of mind. Nature 515, 185-187. doi: $10.1038 / 515185 \mathrm{a}$

Ashton, M. M., Berk, M., Ng, C. H., Hopwood, M., Kavanagh, B., Williams, L. J., et al. (2019). Nutraceuticals and nutritional supplements for the treatment of bipolar disorder: protocol for a systematic review. BMJ Open 9:e025640. doi: 10.1136/bmjopen-2018-025640

Au-Yeung, K. K. W., Yip, J. C. W., Siow, Y. L., and Karmin, O. K. (2006). Folic acid inhibits homocysteine-induced superoxide anion production and nuclear factor kappa B activation in macrophages. Can. J. Physiol. Pharmacol. 84, 141-147. doi: $10.1139 / \mathrm{y} 05-136$

Bagot, R. C., Cates, H. M., Purushothaman, I., Vialou, V., Heller, E. A., Yieh, L., et al. (2017). Ketamine and imipramine reverse transcriptional signatures of susceptibility and induce resilience-specific gene expression profiles. Biol. Psychiatry 81, 285-295. doi: 10.1016/j.biopsych.2016. 06.012

Bakusic, J., Schaufeli, W., Claes, S., and Godderis, L. (2017). Stress, burnout and depression: a systematic review on DNA methylation mechanisms. J. Psychosom. Res. 92, 34-44. doi: 10.1016/j.jpsychores.2016. 11.005

Banasr, M., Dwyer, J. M., and Duman, R. S. (2011). Cell atrophy and loss in depression: reversal by antidepressant treatment. Curr. Opin. Cell Biol. 23, 730-737. doi: 10.1016/j.ceb.2011.09.002

Bang, H. Y., Park, S. A., Saeidi, S., Na, H. K., and Surh, Y. J. (2017). Docosahexaenoic acid induces expression of heme oxygenase-1 and $\mathrm{NAD}(\mathrm{P}) \mathrm{H}$ : quinone oxidoreductase through activation of $\mathrm{Nrf} 2$ in human mammary epithelial cells. Molecules 22:969. doi: 10.3390/molecules22 060969

Bao, A. M., and Swaab, D. F. (2010). Corticotropin-releasing hormone and arginine vasopressin in depression focus on the human postmortem hypothalamus. Vitamins Hormones 82, 339-365. doi: 10.1016/s0083-6729(10) 82018-7

Barnes, P. J. (2013). Theophylline. Am. J. Respir. Crit. Care Med. 188, 901-906.

Bastiaanssen, T. F. S., Cussotto, S., Claesson, M. J., Clarke, G., Dinan, T. G., and Cryan, J. F. (2020). Gutted! unraveling the role of the microbiome in major depressive disorder. Harv. Rev. Psychiatry 28, 26-39. doi: 10.1097/hrp. 0000000000000243

\section{AUTHOR CONTRIBUTIONS}

JA wrote the initial draft of the manuscript. OE edited and rewrote the manuscript, checked, and corrected the references.

\section{FUNDING}

This work was supported from an Advanced Medical Scientist fellowship by the IZKF (Interdisziplinäres Zentrum für Klinische Forschung) of Jena University Hospital, Germany.

Bazinet, R. P., and Layé, S. (2014). Polyunsaturated fatty acids and their metabolites in brain function and disease. Nat. Rev. Neurosci. 15, 771-785. doi: 10.1038/ nrn3820

Bebbington, P. (2001). The World health report 2001 - mental health: new understanding, new hope. Soc. Psychiatry Psychiatr. Epidemiol. 36, 473-474.

Behzadi, A. H., Omrani, Z., Chalian, M., Asadi, S., and Ghadiri, M. (2009). Folic acid efficacy as an alternative drug added to sodium valproate in the treatment of acute phase of mania in bipolar disorder: a double-blind randomized controlled trial. Acta Psychiatr. Scand. 120, 441-445. doi: 10.1111/j.1600-0447. 2009.01368.x

Berger, S. L., and Sassone-Corsi, P. (2016). Metabolic signaling to chromatin. Cold Spring Harb. Perspect. Biol. 8:a019463. doi: 10.1101/cshperspect.a019463

Bhagwagar, Z., Hafizi, S., and Cowen, P. J. (2003). Increase in concentration of waking salivary cortisol in recovered patients with depression. Am. J. Psychiatry 160, 1890-1891. doi: 10.1176/appi.ajp.160.10.1890

Bhattacharya, S. K., Satyan, K. S., and Chakrabarti, A. (1997). Anxiogenic action of caffeine: an experimental study in rats. J. Psychopharmacol. 11, 219-224. doi: 10.1177/026988119701100304

Bjorkholm, C., and Monteggia, L. M. (2016). BDNF - a key transducer of antidepressant effects. Neuropharmacology 102, 72-79. doi: 10.1016/j. neuropharm.2015.10.034

Boneva, N. B., and Yamashima, T. (2012). New insights into "GPR40-CREB interaction inadult neurogenesis" specific for primates. Hippocampus 22, 896905. doi: 10.1002/hipo.20951

Booth, L. N., and Brunet, A. (2016). The aging epigenome. Mol. Cell 62, 728-744. doi: 10.1016/j.molcel.2016.05.013

Bozzatello, P., Brignolo, E., De Grandi, E., and Bellino, S. (2016). Supplementation with Omega-3 fatty acids in psychiatric disorders: a review of literature data. J. Clin. Med. 5:67. doi: 10.3390/jcm5080067

Brown, A. N., and Feng, J. (2017). Drug addiction and DNA modifications. $A d v$. Exp. Med. Biol. 978, 105-125. doi: 10.1007/978-3-319-53889-1_6

Budni, J., Zomkowski, A. D., Engel, D., Santos, D. B., dos Santos, A. A., Moretti, M., et al. (2013). Folic acid prevents depressive-like behavior and hippocampal antioxidant imbalance induced by restraint stress in mice. Exp. Neurol. 240, 112-121. doi: 10.1016/j.expneurol.2012. 10.024

Burrage, E., Marshall, K., Santanam, N., and Chantler, P. (2018). Cerebrovascular dysfunction with stress and depression. Brain Circ. 4, 43-53. doi: 10.4103/bc. bc_6_18

Calderon, F., and Kim, H. Y. (2007). Role of RXR in neurite outgrowth induced by docosahexaenoic acid. Prostagl. Leukot. Essent. Fatty Acids 77, 227-232. doi: 10.1016/j.plefa.2007.10.026

Carek, P. J., Laibstain, S. E., and Carek, S. M. (2011). Exercise for the treatment of depression and anxiety. Int. J. Psychiatry Med. 41, 15-28.

Charney, D. S., Heninger, G. R., and Jatlow, P. I. (1985). Increased anxiogenic effects of caffeine in panic disorders. Arch. Gen. Psychiatry 42, 233-243. doi: 10.1001/archpsyc.1985.01790260 027003

Chaturvedi, S. K., and Upadhyaya, M. (1988). Secondary mania in a patient receiving isonicotinic acid hydrazide and pyridoxine: case report. Can. J. Psychiatry 33, 675-676. doi: 10.1177/070674378803 300729 
Chen, D., Meng, L., Pei, F., Zheng, Y., and Leng, J. (2017). A review of DNA methylation in depression. J. Clin. Neurosci. 43, 39-46.

Chen, E. S., Ernst, C., and Turecki, G. (2011). The epigenetic effects of antidepressant treatment on human prefrontal cortex BDNF expression. Int. J. Neuropsychopharmacol. 14, 427-429. doi: 10.1017/s14611457100 01422

Cho, K., Choi, W. S., Crane, C. L., and Park, C. S. (2014). Pubertal supplementation of lipotropes in female rats reduces mammary cancer risk by suppressing histone deacetylase 1. Eur. J. Nutr. 53, 1139-1143. doi: 10.1007/s00394-0130626-3

CieślikŁupina, T., and Ossowska, G. (2007). Influence of zinc supplementation on imipramine effect in a chronic unpredictable stress (CUS) model in rats. Pharmacol. Rep. 59, 46-52.

Colle, R., De Larminat, D., Rotenberg, S., Hozer, F., Hardy, P., Verstuyft, C., et al. (2017). PPAR- $\gamma$ agonists for the treatment of major depression: a review. Pharmacopsychiatry 50, 49-55. doi: 10.1055/s-0042-12 0120

Connolly, S., and Kingsbury, T. J. (2010). Caffeine modulates CREB-dependent gene expression in developing cortical neurons. Biochem. Biophys. Res. Commun. 397, 152-156. doi: 10.1016/j.bbrc.2010.05.054

Coppen, A., and Bolander-Gouaille, C. (2005). Treatment of depression: time to consider folic acid and vitamin B12. J. Psychopharmacol. 19, 59-65. doi: 10. $1177 / 0269881105048899$

Covington, H. E., Maze, I., LaPlant, Q. C., Vialou, V. F., Ohnishi, Y. N., Berton, O., et al. (2009). Antidepressant actions of histone deacetylase inhibitors. J. Neurosci. 29, 11451-11460.

Crowley, E. K., Long-Smith, C. M., Murphy, A., Patterson, E., Murphy, K., O'Gorman, D. M., et al. (2018). Dietary supplementation with a magnesium-rich marine mineral blend enhances the diversity of gastrointestinal microbiota. Mar. Drugs 16:216. doi: 10.3390/md160 60216

Cubała, W. J., and Landowski, J. (2014). C-reactive protein and cortisol in drug-naïve patients with short-illness-duration first episode major depressive disorder: Possible role of cortisol immunomodulatory action at early stage of the disease. J. Affect. Disord. 29, 169-174. doi: 10.1684/mrh.2016. 0413

Cunha, R. A., Johansson, B., van der Ploeg, I., Sebastião, A. M., Alexandre Ribeiro, J., and Fredholm, B. B. (1994). Evidence for functionally important adenosine A2a receptors in the rat hippocampus. Brain Res. 649, 208-216. doi: 10.1016/ 0006-8993(94)91066-9

Czarny, P., Wigner, P., Galecki, P., and Sliwinski, T. (2018). The interplay between inflammation, oxidative stress, DNA damage, DNA repair and mitochondrial dysfunction in depression. Prog. Neuro Psychopharmacol. Biol. Psychiatry 80, 309-321. doi: 10.1016/j.pnpbp.2017.06.036

Dawson, V. L., Dawson, T. M., London, E. D., Bredt, D. S., and Snyder, S. H. (1991). Nitric oxide mediates glutamate neurotoxicity in primary cortical cultures. Proc. Natl. Acad. Sci. U.S.A. 88, 6368-6371. doi: 10.1073/pnas.88.14.6368

De Berardis, D., Orsolini, L., Serroni, N., Girinelli, G., Iasevoli, F., Tomasetti, C., et al. (2016). A comprehensive review on the efficacy of S-Adenosyl-Lmethionine in major depressive disorder. CNS Neurol. Disord. Drug Targets 15, 35-44. doi: 10.2174/1871527314666150821103825

Dias Alves, M., Varin, L., Fiori, L. M., Etain, B., Azorin, J. M., and Belzeaux, R. (2017). Efficacy of vitamin B6 in lithium-associated tremor: a case series. J. Clin. Psychopharmacol. 37, 267-269. doi: 10.1097/jcp.0000000000 000650

Djuric, D., Jakovljevic, V., Zivkovic, V., and Srejovic, I. (2018). Homocysteine and homocysteine-related compounds: an overview of the roles in the pathology of the cardiovascular and nervous systems. Can. J. Physiol. Pharmacol. 96, 991-1003. doi: 10.1139/cjpp-201 8-0112

Doboszewska, U., Szewczyk, B., Sowa-Kuæma, M., Noworyta-Sokołowska, K., Misztak, P., Gołêbiowska, J., et al. (2016). Alterations of bio-elements, oxidative, and inflammatory status in the zinc deficiency model in rats. Neurotoxic. Res. 29, 143-154. doi: 10.1007/s12640-015-9571-7

Dong, X., Tang, S., Zhang, W., Gao, W., and Chen, Y. (2016). GPR39 activates proliferation and differentiation of porcine intramuscular preadipocytes through targeting the PI3K/AKT cell signaling pathway.
J. Recept. Signal Trans. 36, 130-138. doi: 10.3109/10799893.2015.10 56308

Dwivedi, Y., Rizavi, H. S., Conley, R. R., Roberts, R. C., Tamminga, C. A., and Pandey, G. N. (2003). Altered gene expression of brain-derived neurotrophic factor and receptor tyrosine kinase $\mathrm{B}$ in postmortem brain of suicide subjects. Arch. Gen. Psychiatry 60, 804-815. doi: 10.1001/archpsyc.60. 8.804

Dyzma, M., Boudjeltia, K. Z., Faraut, B., and Kerkhofs, M. (2010). Neuropeptide Y and sleep. Sleep Med. Rev. 14, 161-165. doi: 10.1016/j.smrv.2009.09.001

Eby, G. A., and Eby, K. L. (2006). Rapid recovery from major depression using magnesium treatment. Med. Hypotheses 67, 362-370. doi: 10.1016/j.mehy.2006. 01.047

Edgar, N., and Mcclung, C. (2013). Major depressive disorder: a loss of circadian synchrony? BioEssays 35, 940-944. doi: 10.1002/bies.201300086

Endesfelder, S., Weichelt, U., Strauß, E., Schlör, A., Sifringer, M., Scheuer, T., et al. (2017). Neuroprotection by caffeine in hyperoxia-induced neonatal brain injury. Int. J. Mol. Sci. 18:187. doi: 10.3390/ijms18 010187

Engmann, O., Giralt, A., and Girault, J. (2016). Acute drug-induced spine changes in the nucleus accumbens are dependent on beta-adducin. Neuropharmacology 110, 333-342. doi: 10.1016/j.neuropharm.2016. 07.035

Ernst, C., Chen, E. S., and Turecki, G. (2009). Histone methylation and decreased expression of TrkB.T1 in orbital frontal cortex of suicide completers. Mol. Psychiatry 14, 830-832. doi: $10.1038 / \mathrm{mp} .2009 .35$

Fava, M., and Mischoulon, D. (2009). Folate in depression: efficacy, safety, differences in formulations, and clinical issues. J. Clin. Psychiatry 70(Suppl. 5), 12-17. doi: $10.4088 /$ jcp. 8157 sulc.03

Ferrari, F., and Villa, R. F. (2017). The neurobiology of depression: an integrated overview from biological theories to clinical evidence. Mol. Neurobiol. 54, 4847-4865. doi: 10.1007/s12035-016-0032-y

Ferraz, A. C., Delattre, A. M., Almendra, R. G., Sonagli, M., Borges, C., Araujo, P., et al. (2011). Chronic $\omega-3$ fatty acids supplementation promotes beneficial effects on anxiety, cognitive and depressive-like behaviors in rats subjected to a restraint stress protocol. Behav. Brain Res. 219, 116-122. doi: 10.1016/j.bbr. 2010.12.028

Ferré, S. (2013). Caffeine and substance use disorders. J. Caffeine Res. 3, 57-58. doi: $10.1089 /$ jcr.2013.0015

Fiori, L. M., Gross, J. A., and Turecki, G. (2012). Effects of histone modifications on increased expression of polyamine biosynthetic genes in suicide. Int. J. Neuropsychopharmacol. 15, 1161-1166. doi: 10.1017/s14611457110 01520

Frederickson, C. J., Suh, S. W., Silva, D., Frederickson, C. J., and Thompson, R. B. (2000). Importance of zinc in the central nervous system: the zinc-containing neuron. J. Nutr. 130, 1471S-1483S.

Froese, D. S., Fowler, B., and Baumgartner, M. R. (2019). Vitamin B12, folate, and the methionine remethylation cycle-biochemistry, pathways, and regulation. J. Inherited Metab. Dis. 42, 673-685. doi: 10.1002/jimd. 12009

Fuxe, K., Ferré, S., Genedani, S., Franco, R., and Agnati, L. F. (2007). Adenosine receptor-dopamine receptor interactions in the basal ganglia and their relevance for brain function. Physiol. Behav. 92, 210-217. doi: 10.1016/j. physbeh.2007.05.034

Garza, J. C., Guo, M., Zhang, W., and Lu, X. Y. (2012). Leptin restores adult hippocampal neurogenesis in a chronic unpredictable stress model of depression and reverses glucocorticoid-induced inhibition of GSK3B/B-catenin signaling. Mol. Psychiatry 17, 790-808. doi: 10.1038/mp.20 11.161

Ghosh, S., Sinha, J. K., Khandelwal, N., Chakravarty, S., Kumar, A., and Raghunath, M. (2018). Increased stress and altered expression of histone modifying enzymes in brain are associated with aberrant behaviour in vitamin B12 deficient female mice. Nutr. Neurosci. 1, 1-10.

Ghoshal, K., Li, X., Datta, J., Bai, S., Pogribny, I., Pogribny, M., et al. (2006). A folate- and methyl-deficient diet alters the expression of DNA methyltransferases and methyl CpG binding proteins involved in epigenetic gene silencing in livers of F344 rats. J. Nutr. 136, 1522-1527. doi: 10.1093/jn/ 136.6.1522 
Gibson, R. A., and Makrides, M. (2001). Long-chain polyunsaturated fatty acids in breast milk: are they essential? Adv. Exp. Med. Biol. 501, 175-183.

Gibson, R. S., Bailey, K. B., Gibbs, M., and Ferguson, E. L. (2010). A review of phytate, iron, zinc, and calcium concentrations in plant-based complementary foods used in low-income countries and implications for bioavailability. Food Nutr. Bull. 31(Suppl. 2), S134-S146.

Gilbody, S., Lightfoot, T., and Sheldon, T. (2007). Is low folate a risk factor for depression? A meta-analysis and exploration of heterogeneity. J. Epidemiol. Commun. Health 61, 631-637. doi: 10.1136/jech.2006. 050385

Golden, R. N., Gaynes, B. N., Ekstrom, R. D., Hamer, R. M., Jacobsen, F. M., Suppes, T., et al. (2005). The efficacy of light therapy in the treatment of mood disorders: a review and meta-analysis of the evidence. Am. J. Psychiatry 162, 656-662. doi: 10.1176/appi.ajp.162.4.656

González-Becerra, K., Ramos-Lopez, O., Barrón-Cabrera, E., Riezu-Boj, J. I., Milagro, F. I., Martínez-López, E., et al. (2019). Fatty acids, epigenetic mechanisms and chronic diseases: a systematic review. Lipids Health Dis. $18: 178$.

Górska, N., Sáupski, J., Szaáach, ŁP., Wáodarczyk, A., Szarmach, J., JakuszkowiakWojten, K., et al. (2019). Magnesium and ketamine in the treatment of depression. Psychiatr. Danubina 31(Suppl. 3), 549-553.

Gougeon, L. (2014). Nutritional predictors of depression in a cohort of community-dwelling elderly canadians: Nuage cohort. Appl. Physiol. Nutr. Metab. 19, 431-436.

Greenberg, P. E., Fournier, A. A., Sisitsky, T., Pike, C. T., and Kessler, R. C. (2015). The economic burden of adults with major depressive disorder in the United States (2005 and 2010). J. Clin. Psychiatry 76, 155-162. doi: 10.4088/jcp. $14 \mathrm{~m} 09298$

Grieve, S. M., Korgaonkar, M. S., Koslow, S. H., Gordon, E., and Williams, L. M. (2013). Widespread reductions in gray matter volume in depression. NeuroImage 3, 332-339. doi: 10.1016/j.nicl.2013.08.016

Grosso, G., Galvano, F., Marventano, S., Malaguarnera, M., Bucolo, C. Drago, F., et al. (2014). Omega-3 fatty acids and depression: Scientific evidence and biological mechanisms. Oxid. Med. Cell. Longev. 2014: 313570 .

Guillemin, G. J. (2012). Quinolinic acid, the inescapable neurotoxin. FEBS J. 279, 1356-1365. doi: 10.1111/j.1742-4658.2012.08485.x

Guo, M., and Lu, X. Y. (2014). Leptin receptor deficiency confers resistance to behavioral effects of fluoxetine and desipramine via separable substrates. Transl. Psychiatry 4:e486. doi: 10.1038/tp.2014.126

Hall, S., Desbrow, B., Anoopkumar-Dukie, S., Davey, A. K., Arora, D., McDermott, C., et al. (2015). A review of the bioactivity of coffee, caffeine and key coffee constituents on inflammatory responses linked to depression. Food Res. Int. 76(Pt 3), 626-636. doi: 10.1016/j.foodres.2015. 07.027

Hamon, M., and Blier, P. (2013). Monoamine neurocircuitry in depression and strategies for new treatments. Prog. Neuro Psychopharmacol. Biol. Psychiatry 45, 54-63. doi: 10.1016/j.pnpbp.2013.04.009

Harmer, C. J., Duman, R. S., and Cowen, P. J. (2017). How do antidepressants work? New perspectives for refining future treatment approaches. Lancet Psychiatry 4 , 409-418. doi: 10.1016/s2215-0366(17)30015-9

Heilig, M. (2004). The NPY system in stress, anxiety and depression. Neuropeptides 38, 213-224. doi: 10.1016/j.npep.2004.05.002

Henje Blom, E., Han, L. K. M., Connolly, C. G., Ho, T. C., Lin, J., LeWinn, K. Z., et al. (2015). Peripheral telomere length and hippocampal volume in adolescents with major depressive disorder. Transl. Psychiatry 5:e676. doi: $10.1038 /$ tp. 2015.172

Hershfinkel, M. (2018). The zinc sensing receptor, ZnR/GPR39, in health and disease. Int. J. Mol. Sci. 19:439. doi: 10.3390/ijms19020439

Heuser, I. (2002). Depression, endocrinologically a syndrome of premature aging? Maturitas 41(Suppl. 1), S19-S23.

Hidaka, B. H. (2012). Depression as a disease of modernity: explanations for increasing prevalence. J. Affect. Disord. 140, 205-214. doi: 10.1016/j.jad.2011. 12.036

Höglund, E., Øverli, $\varnothing$, and Winberg, S. (2019). Tryptophan metabolic pathways and brain serotonergic activity: a comparative review. Front. Endocrinol. 10:158. doi: 10.3389/fendo.2019.00158
Holst, B., Egerod, K. L., Schild, E., Vickers, S. P., Cheetham, S., Gerlach, L. O., et al. (2007). GPR39 signaling is stimulated by zinc ions but not by obestatin. Endocrinology 148, 13-20. doi: 10.1210/en.2006-0933

Hongxia, L., Yuxiao, T., Zhilei, S., Yan, S., Yicui, Q., Jiamin, S., et al. (2019). Zinc inhibited LPS-induced inflammatory responses by upregulating A20 expression in microglia BV2 cells. J. Affect. Disord. 249, 136-142. doi: 10.1016/j.jad.2019. 02.041

Howren, M. B., Lamkin, D. M., and Suls, J. (2009). Associations of depression with c-reactive protein, IL-1, and IL-6: A meta-analysis. Psychosom. Med. 71, 171-186. doi: 10.1097/psy.0b013e3181907c1b

Hsieh, Y. C., Chou, L. S., Lin, C. H., Wu, H. C., Li, D. J., and Tseng, P. T. (2019). Serum folate levels in bipolar disorder: a systematic review and meta-analysis. BMC Psychiatry 19:305. doi: 10.1186/s12888-019-2269-2

Hvas, A. M., Juul, S., Bech, P., and Nexø, E. (2004). Vitamin B 6 level is associated with symptoms of depression. Psychother. Psychosom. 73, 340-343. doi: 10. $1159 / 000080386$

Jiang, H., Ling, Z., Zhang, Y., Mao, H., Ma, Z., Yin, Y., et al. (2015). Altered fecal microbiota composition in patients with major depressive disorder. Brain Behav. Immun. 48, 186-194. doi: 10.1016/j.bbi.2015. 03.016

Jung, H. Y., Kwon, H. J., Kim, W., Nam, S. M., Kim, J. W., Hahn, K. R., et al. (2019). Role of pyridoxine in GABA synthesis and degradation in the hippocampus. Tissue Cell 61, 72-78. doi: 10.1016/j.tice.2019.09.005

Kafeshani, M., Feizi, A., Esmaillzadeh, A., Keshteli, A. H., Afshar, H., Roohafza, H., et al. (2019). Higher vitamin B 6 intake is associated with lower depression and anxiety risk in women but not in men: a large cross-sectional study. Int. J. Vitamin Nutr. Res. 1, 1-9.

Kan, C., Silva, N., Golden, S. H., Rajala, U., Timonen, M., Stahl, D., et al. (2013). A systematic review and meta-analysis of the association between depression and insulin resistance. Diab. Care 36, 480-489.

Kapadia, R., Yi, J. H., and Vemuganti, R. (2008). Mechanisms of anti-inflammatory and neuroprotective actions of PPAR-gamma agonists. Front. Biosci. 13:18131826. doi: $10.2741 / 2802$

Karas Kuželièki, N. (2016). S-Adenosyl methionine in the therapy of depression and other psychiatric disorders. Drug Dev. Res. 77, 346-356. doi: 10.1002/ddr. 21345

Kasahara, T., and Kato, T. (2018). What can mitochondrial DNA analysis tell us about mood disorders? Biol. Psychiatry 83, 731-738. doi: 10.1016/j.biopsych. 2017.09.010

Kato, T. (2017). Neurobiological basis of bipolar disorder: mitochondrial dysfunction hypothesis and beyond. Schizophrenia Res. 187, 62-66. doi: 10 1016/j.schres.2016.10.037

Kendler, K. S. (2001). Twin studies of psychiatric illness: an update. Arch. Gen. Psychiatry 58, 1005-1014. doi: 10.1001/archpsyc.58.11.1005

Kiec-Wilk, B., Sliwa, A., Mikolajczyk, M., Malecki, M. T., and Mathers, J. C. (2011). The CpG island methylation regulated expression of endothelial proangiogenic genes in response to $\beta$-carotene and arachidonic acid. Nutr. Cancer 63, 1053-1063. doi: 10.1080/01635581.2011. 596644

Kiessling, S., Eichele, G., and Oster, H. (2010). Adrenal glucocorticoids have a key role in circadian resynchronization in a mouse model of jet lag. J. Clin. Invest. 120, 2600-2609. doi: 10.1172/JCI41192

Kim, H. W., Rapoport, S. I., and Rao, J. S. (2011). Altered arachidonic acid cascade enzymes in postmortem brain from bipolar disorder patients. Mol. Psychiatry 16, 419-428. doi: 10.1038/mp.2009.137

Kinser, P. A., and Lyon, D. E. (2013). Major depressive disorder and measures of cellular aging: an integrative review. Nurs. Res. Pract. 2013:469070.

Kishi, T., Yoshimura, R., Kitajima, T., Okochi, T., Okumura, T., Tsunoka, T., et al. (2010). SIRT1 gene is associated with major depressive disorder in the Japanese population. J. Affect. Disord. 126, 167-173. doi: 10.1016/j.jad.2010. 04.003

Klug, A. (2010). The discovery of zinc fingers and their applications in gene regulation and genome manipulation. Annu. Rev. Biochem. 79, 213-231. doi: 10.1146/annurev-biochem-010909-095056

Krishnan, V., and Nestler, E. J. (2010). Linking molecules to mood: new insight into the biology of depression. Am. J. Psychiatry 167, 1305-1320. doi: 10.1176/appi. ajp.2009.10030434 
Kroczka, B., Zieba, A., Dudek, D., Pilc, A., and Nowak, G. (2000). Zinc exhibits an antidepressant-like effect in the forced swimming test in mice. Polish J. Pharmacol. 52, 403-406.

Krystal, J. H., Abdallah, C. G., Sanacora, G., Charney, D. S., and Duman, R. S. (2019). Ketamine: a paradigm shift for depression research and treatment. Neuron 101, 774-778. doi: 10.1016/j.neuron.2019.02.005

Kulkarni, A., Dangat, K., Kale, A., Sable, P., Chavan-Gautam, P., and Joshi, S. (2011). Effects of altered maternal folic acid, vitamin B12 and docosahexaenoic acid on placental global DNA methylation patterns in wistar rats. PLoS One 6:e17706. doi: 10.1371/journal.pone.0017706

Kunii, Y., Hyde, T. M., Ye, T., Li, C., Kolachana, B., Dickinson, D., et al. (2014). Revisiting DARPP-32 in postmortem human brain: changes in schizophrenia and bipolar disorder and genetic associations with t-DARPP-32 expression. Mol. Psychiatry 19, 192-199. doi: 10.1038/mp.2012.174

Labonte, B., Engmann, O., Purushothaman, I., Hodes, G., Lorsch, Z. S., and Hamilton, P. J. (2017). Sex-specific transcriptional signatures in human depression. Nat. Med. 23, 1102-1111.

Landgraf, D., McCarthy, M. J., and Welsh, D. K. (2014) Circadian clock and stress interactions in the molecular biology of psychiatric disorders. Curr. Psychiatry Rep. 16:483. doi: 10.1007/s11920-014-0483-7

Lao-Peregrín, C., Ballesteros, J. J., Fernández, M., Zamora-Moratalla, A., Saavedra, A., Gómez Lázaro, M., et al. (2017). Caffeine-mediated BDNF release regulates long-term synaptic plasticity through activation of IRS2 signaling. Addict. Biol. 22, 1706-1718. doi: 10.1111/adb.12433

Larrieu, T., Hilal, L. M., Fourrier, C., De Smedt-Peyrusse, V., Sans, N., Capuron, L., et al. (2014). Nutritional omega-3 modulates neuronal morphology in the prefrontal cortex along with depression-related behavior through corticosterone secretion. Transl. Psychiatry 4:e437. doi: 10.1038/tp.2014.77

Larrieu, T., and Layé, S. (2018). Food for mood: relevance of nutritional omega-3 fatty acids for depression and anxiety. Front. Physiol. 9:1047. doi: 10.3389/fphys. 2018.01047

Layé, S., Nadjar, A., Joffre, C., and Bazinet, R. P. (2018). Anti-inflammatory effects of omega-3 fatty acids in the brain: physiological mechanisms and relevance to pharmacology. Pharmacol. Rev. 70, 12-38. doi: 10.1124/pr.117.014092

Ledford, H. (2015). First robust genetic links to depression emerge. Nature 523, 268-269. doi: 10.1038/523268a

Lee, C., Kim, B. G., Kim, J. H., Chun, J., Im, J. P., and Kim, J. S. (2017). Sodium butyrate inhibits the NF-kappa B signaling pathway and histone deacetylation, and attenuates experimental colitis in an IL-10 independent manner. Int. Immunopharmacol. 51, 47-56. doi: 10.1016/j.intimp.2017. 07.023

Lee, R. G., Rains, T. M., Tovar-Palacio, C., Beverly, J. L., and Shay, N. F. (1998). Zinc deficiency increases hypothalamic neuropeptide $\mathrm{Y}$ and neuropeptide $\mathrm{Y}$ mRNA levels and does not block neuropeptide Y-induced feeding in rats. J. Nutr. 128, 1218-1223. doi: 10.1093/jn/128.7.1218

Lepack, A. E., Werner, C. T., Stewart, A. F., Fulton, S. L., Zhong, P., Farrelly, L. A., et al. (2020). Dopaminylation of histone H3 in ventral tegmental area regulates cocaine seeking. Science 368, 197-201. doi: 10.1126/science. aaw8806

Levenson, C. W. (2003). Zinc regulation of food intake: new insights on the role of neuropeptide Y. Nutr. Rev. 61, 247-249. doi: 10.1301/nr.2003.jul.247-249

Levy, M. J. F., Boulle, F., Steinbusch, H. W., van den Hove, D. L. A., Kenis, G., and Lanfumey, L. (2018). Neurotrophic factors and neuroplasticity pathways in the pathophysiology and treatment of depression. Psychopharmacology 235, 2195-2220. doi: 10.1007/s00213-018-4950-4

Lin, P., Ding, B., Feng, C., Yin, S., Zhang, T., Qi, X., et al. (2017). Prevotella and Klebsiella proportions in fecal microbial communities are potential characteristic parameters for patients with major depressive disorder. J. Affect. Disord. 207, 300-304. doi: 10.1016/j.jad.2016.09.051

Lindskog, M., Svenningsson, P., Pozzi, L., Kim, Y., Fienberg, A. A., Bibb, J. A., et al. (2002). Involvement of DARPP-32 phosphorylation in the stimulant action of caffeine. Nature 418, 774-778. doi: 10.1038/nature 00817

Lipton, S. A., Kim, W. K., Choi, Y. B., Kumar, S., D’Emilia, D. M., Rayudu, P. V., et al. (1997). Neurotoxicity associated with dual actions of homocysteine at the N-methyl-D-aspartate receptor. Proc. Natl. Acad. Sci. U.S.A. 94, 5923-5928. doi: 10.1073/pnas.94.11.5923
Lu, G., Li, J., Zhang, H., Zhao, X., Yan, L. J., and Yang, X. (2018). Role and possible mechanisms of sirt1 in depression. Oxid. Med. Cell. Longev. 2018:8596903.

Lucas, M. (2011). Coffee, caffeine, and risk of depression among women. Arch. Intern. Med. 171:1571. doi: 10.1001/archinternmed.2011.393

Machado, D. G., Lara, M. V. S., Dobler, P. B., Almeida, R. F., and Porciúncula, L. O. (2020). Caffeine prevents neurodegeneration and behavioral alterations in a mice model of agitated depression. Prog. Neuro Psychopharmacol. Biol. Psychiatry 98:109776. doi: 10.1016/j.pnpbp.2019. 109776

Maes, M., D’Haese, P. C., Scharpé, S., D’Hondt, P., Cosyns, P., and De Broe, M. E. (1994). Hypozincemia in depression. J. Affect. Disord. 31, 135-140. doi: 10.1016/0165-0327(94)90117-1

Maguire, D., Neytchev, O., Talwar, D., McMillan, D., and Shiels, P. G. (2018). Telomere homeostasis: interplay with magnesium. Int. J. Mol. Sci. 19:157. doi: 10.3390/ijms19010157

Mann, J. J., and Currier, D. (2006). Effects of genes and stress on the neurobiology of depression. Int. Rev. Neurobiol. 73, 153-189. doi: 10.1016/s0074-7742(06) 73005-7

Marion-Letellier, R., Savoye, G., and Ghosh, S. (2016). Fatty acids, eicosanoids and PPAR gamma. Eur. J. Pharmacol. 785, 44-49. doi: 10.1016/j.ejphar.2015.11.004

Markowitz, J. C., and Weissman, M. M. (2004). Interpersonal psychotherapy: principles and applications. World Psychiatry 3, 136-139.

Matosin, N., Cruceanu, C., and Binder, E. B. (2017). Preclinical and clinical evidence of DNA methylation changes in response to trauma and chronic stress. Chron. Stress 1:2470547017710764.

Maussion, G., Yang, J., Suderman, M., Diallo, A., Nagy, C., Arnovitz, M., et al. (2014). Functional DNA methylation in a transcript specific 3'UTR region of TrkB associates with suicide. Epigenetics 9, 1061-1070. doi: 10.4161/epi. 29068

McCarty, M. F. (2000). High dose pyridoxine as an "anti-stress" strategy. Med. Hypotheses 54, 803-807. doi: 10.1054/mehy.1999.0955

McClung, C. (2007a). Circadian genes, rhythms and the biology of mood disorders. Pharmacol. Ther. 114, 222-232. doi: 10.1016/j.pharmthera.2007.02.003

McClung, C. (2007b). Role for the Clock gene in bipolar disorder. Cold Spring Harb. Symp. Quant. Biol. 72, 637-644.

McCoy, C. R., Rana, S., Stringfellow, S. A., Day, J. J., Wyss, J. M., Clinton, S. M., et al. (2016). Neonatal maternal separation stress elicits lasting DNA methylation changes in the hippocampus of stress-reactive Wistar Kyoto rats. Eur. J. Neurosci. 44, 2829-2845. doi: 10.1111/ejn. 13404

McEwen, B. S. (2017). Neurobiological and systemic effects of chronic stress. Chron. Stress 1:2470547017692328.

Meier, T. B., Drevets, W. C., Wurfel, B. E., Ford, B. N., Morris, H. M., Victor, T. A., et al. (2016). Relationship between neurotoxic kynurenine metabolites and reductions in right medial prefrontal cortical thickness in major depressive disorder. Brain Behav. Immun. 53, 39-48. doi: 10.1016/j.bbi.2015. 11.003

Mendoza, J. (2019). Circadian insights into the biology of depression: Symptoms, treatments and animal models. Behav. Brain Res. 376:112186. doi: 10.1016/j. bbr.2019.112186

Menegas, S., Dal-Pont, G. C., Cararo, J. H., Varela, R. B., Aguiar-Geraldo, J. M., Possamai-Della, T., et al. (2020). Efficacy of folic acid as an adjunct to lithium therapy on manic-like behaviors, oxidative stress and inflammatory parameters in an animal model of mania. Metab. Brain Dis. 35, 413-425. doi: 10.1007/ s11011-019-00503-3

Mesripour, A., Alhimma, F., and Hajhashemi, V. (2019). The effect of vitamin B6 on dexamethasone-induced depression in mice model of despair. Nutr. Neurosci. 22, 744-749. doi: 10.1080/1028415x.2018.14 42184

Mesripour, A., Hajhashemi, V., and Kuchak, A. (2017). Effect of concomitant administration of three different antidepressants with vitamin B6 on depression and obsessive compulsive disorder in mice models. Res. Pharm. Sci. 12, 46-52. doi: 10.4103/1735-5362.199046

Meyer, J. H., Ginovart, N., Boovariwala, A., Sagrati, S., Hussey, D., Garcia, A., et al. (2006). Elevated monoamine oxidase A levels in the brain: an explanation for the monoamine imbalance of major depression. 
Arch. Gen. Psychiatry 63, 1209-1216. doi: 10.1001/archpsyc.63.11. 1209

Mikkelsen, K., Stojanovska, L., and Apostolopoulos, V. (2016). The effects of vitamin B in depression. Curr. Med. Chem. 23, 4317-4337. doi: 10.2174/ 0929867323666160920110810

Mikkelsen, K., Stojanovska, L., Prakash, M., and Apostolopoulos, V. (2017). The effects of vitamin B on the immune/cytokine network and their involvement in depression. Maturitas 96, 58-71. doi: 10.1016/j.maturitas.2016.11.012

Milaneschi, Y., Simmons, W. K., van Rossum, E. F. C., and Penninx, B. W. (2019). Depression and obesity: evidence of shared biological mechanisms. Mol. Psychiatry 24, 18-33. doi: 10.1038/s41380-018-0017-5

Miller, A. H., Maletic, V., and Raison, C. L. (2009). Inflammation and its discontents: the role of cytokines in the pathophysiology of major depression. Biol. Psychiatry 65, 732-741. doi: 10.1016/j.biopsych.2008. 11.029

Miller, A. L. (2008). The methylation, neurotransmitter, and antioxidant connections between folate and depression. Altern. Med. Rev. 13, 216-226.

Minami, A., Takeda, A., Yamaide, R., and Oku, N. (2002). Relationship between zinc and neurotransmitters released into the amygdalar extracellular space. Brain Res. 936, 91-94. doi: 10.1016/s0006-8993(02) 02499-x

Miura, H., Ozaki, N., Sawada, M., Isobe, K., Ohta, T., and Nagatsu, T. (2008). A link between stress and depression: shifts in the balance between the kynurenine and serotonin pathways of tryptophan metabolism and the etiology and pathophysiology of depression. Stress 11, 198-209. doi: 10.1080/ 10253890701754068

Mlyniec, K., Budziszewska, B., Holst, B., Ostachowicz, B., and Nowak, G. (2015). GPR39 (zinc receptor) knockout mice exhibit depression-like behavior and CREB/BDNF down-regulation in the hippocampus. Int. J. Neuropsychopharmacol. 18:yu002.

Młyniec, K., Singewald, N., Holst, B., and Nowak, G. (2015). GPR39 Zn2+-sensing receptor: a new target in antidepressant development? J. Affect. Disord. 174, 89-100. doi: 10.1016/j.jad.2014.11.033

Mocking, R. J. T., Ruhé, H. G., Assies, J., Lok, A., Koeter, M. W. J., Visser, I., et al. (2013). Relationship between the hypothalamic-pituitary-adrenal-axis and fatty acid metabolism in recurrent depression. Psychoneuroendocrinology 38, 1607-1617. doi: 10.1016/j.psyneuen.2013.01.013

Monroy-Jaramillo, N., Dyukova, E., and Walss-Bass, C. (2018). Telomere length in psychiatric disorders: Is it more than an ageing marker? World J. Biol. Psychiatry 19(Suppl. 2), S2-S20.

Moore, K., Hughes, C. F., Hoey, L., Ward, M., Cunningham, C., Molloy, A. M., et al. (2019). B-vitamins in relation to depression in older adults over 60 years of age: the trinity ulster department of agriculture (TUDA) cohort study. J. Am. Med. Dir. Assoc. 20, 551-557. doi: 10.1016/j.jamda.2018.11.031

Moore, K., Hughes, C. F., Ward, M., Hoey, L., and McNulty, H. (2018). Diet, nutrition and the ageing brain: current evidence and new directions. Proc. Nutr. Soc. 77, 152-163. doi: 10.1017/s0029665117004177

Morales-Medina, J. C., Dumont, Y., and Quirion, R. (2010). A possible role of neuropeptide $\mathrm{Y}$ in depression and stress. Brain Res. 1613, 194-205. doi: 10. 1016/j.brainres.2009.09.077

Morgese, M. G., Tucci, P., Mhillaj, E., Bove, M., Schiavone, S., Trabace, L., et al. (2017). Lifelong nutritional Omega-3 deficiency evokes depressive-like state through soluble beta amyloid. Mol. Neurobiol. 54, 2079-2089. doi: 10.1007/ s12035-016-9809-2

Moustafa, A. A., Hewedi, D. H., Eissa, A. M., Frydecka, D., and Misiak, B. (2014). Homocysteine levels in schizophrenia and affective disorders-focus on cognition. Front. Behav. Neurosci. 8:343. doi: 10.3389/fnbeh.2014.00343

Mrazek, D. A., Hornberger, J. C., Altar, C. A., and Degtiar, I. (2014). A review of the clinical, economic, and societal burden of treatment-resistant depression: 1996-2013. Psychiatr. Serv. 65, 977-987. doi: 10.1176/appi.ps.2013 00059

Murakami, K., Mizoue, T., Sasaki, S., Ohta, M., Sato, M., Matsushita, Y., et al. (2008). Dietary intake of folate, other B vitamins, and $\omega-3$ polyunsaturated fatty acids in relation to depressive symptoms in Japanese adults. Nutrition 24, 140-147. doi: 10.1016/j.nut.2007.10.013

Murck, H. (2013). Ketamine, magnesium and major depression - from pharmacology to pathophysiology and back. J. Psychiatr. Res. 47, 955-965. doi: 10.1016/j.jpsychires.2013.02.015
Murphy, M. J., and Peterson, M. J. (2015). Sleep disturbances in depression. Sleep Med. Clin. 10, 17-23. doi: 10.1016/j.jsmc.2014.11.009

Nestler, E. J., Peñ;a, C. J., Kundakovic, M., Mitchell, A., and Akbarian, S. (2015). Epigenetic basis of mental illness. Neuroscientist 22, 447-463. doi: 10.1177/ 1073858415608147

Nierenberg, A. A., Montana, R., Kinrys, G., Deckersbach, T., Dufour, S., and Baek, J. H. (2017). L-Methylfolate For Bipolar I depressive episodes: an open trial proof-of-concept registry. J. Affect. Disord. 207, 429-433. doi: 10.1016/j.jad. 2016.09.053

Nishinaka, T., Yamashita, T., Nakamoto, K., Kasuya, F., and Tokuyama, S. (2014). Involvement of the long-chain fatty acid receptor GPR40 in depression-related behavior. J. Pharmacol. Sci. 125, 112-115. doi: 10.1254/jphs. $14001 \mathrm{sc}$

Nowak, G., Siwek, M., Dudek, D., Zieba, A., and Pilc, A. (2003a). Effect of zinc supplementation on antidepressant therapy in unipolar depression: a preliminary placebo-controlled study. Polish J. Pharmacol. 55, 1143-1147.

Nowak, G., Szewczyk, B., Wieronska, J. M., Branski, P., Palucha, A., Pilc, A., et al. (2003b). Antidepressant-like effects of acute and chronic treatment with zinc in forced swim test and olfactory bulbectomy model in rats. Brain Res. Bull. 61, 159-164. doi: 10.1016/s0361-9230(03)00104-7

Obeid, R., and Herrmann, W. (2006). Mechanisms of homocysteine neurotoxicity in neurodegenerative diseases with special reference to dementia. FEBS Lett. 580, 2994-3005. doi: 10.1016/j.febslet.2006.04.088

Okereke, O. I., Cook, N. R., Albert, C. M., Van Denburgh, M., Buring, J. E., and Manson, J. A. E. (2015). Effect of long-term supplementation with folic acid and B vitamins on risk of depression in older women. Br. J. Psychiatry 206, 324-331. doi: 10.1192/bjp.bp.114.148361

O'Reardon, J. P., Cristancho, P., and Peshek, A. D. (2006). Vagus nerve stimulation (VNS) and treatment of depression: to the brainstem and beyond. Psychiatry 3 , 54-63.

Palma-Gudiel, H., Córdova-Palomera, A., Navarro, V., and Fañanás, L. (2020). Twin study designs as a tool to identify new candidate genes for depression: a systematic review of DNA methylation studies. Neurosci. Biobehav. Rev. 112, 345-352. doi: 10.1016/j.neubiorev.2020.02.017

Papakostas, G. I., and Ionescu, D. F. (2015). Towards new mechanisms: an update on therapeutics for treatment-resistant major depressive disorder. Mol. Psychiatry 20, 1142-1150. doi: 10.1038/mp.2015.92

Pariante, C. M., and Lightman, S. L. (2008). The HPA axis in major depression: classical theories and new developments. Trends Neurosci. 31, 464-468. doi: 10.1016/j.tins.2008.06.006

Paternain, L., Martisova, E., Campi??n, J., Mart??nez, J. A., Ram??rez, M. J., and Milagro, F. I (2016). Methyl donor supplementation in rats reverses the deleterious effect of maternal separation on depressionlike behaviour. Behav. Brain Res. 299, 51-58. doi: 10.1016/j.bbr.2015. 11.031

Pechlivanova, D., Tchekalarova, J., Alova, L., Petkov, V., Nikolov, R., and Yakimova, K. (2012). Effect of long-term caffeine administration on depressive-like behavior in rats exposed to chronic unpredictable stress. Behav. Pharmacol. 23, 339-347. doi: 10.1097/fbp.0b013e3283564dd9

Peña, C. J., and Nestler, E. J. (2018). Progress in epigenetics of depression. Prog. Mol. Biol. Transl. Sci. 157, 41-66. doi: 10.1016/bs.pmbts.2017.12.011

Penner-Goeke, S., and Binder, E. B. (2019). Epigenetics and depression. Dial. Clin. Neurosci. 21, 397-405. doi: 10.31887/dcns.2019. 21.4/ebinder

Permoda-Osip, A., Dorszewska, J., Skibinska, M., Chlopocka-Wozniak, M., and Rybakowski, J. K. (2013). Hyperhomocysteinemia in bipolar depression: clinical and biochemical correlates. Neuropsychobiology 68, 193-196. doi: 10.1159/ 000355292

Peters, S., Koh, J., and Choi, D. W. (1987). Zinc selectively blocks the action of N-methyl-D-aspartate on cortical neurons. Science 236, 589-593. doi: 10.1126/ science. 2883728

Phillips, J. E., and Corces, V. G. (2009). CTCF: master weaver of the genome. Cell 137, 1194-1211. doi: 10.1016/j.cell.2009.06.001

Pochwat, B., Sowa-Kucma, M., Kotarska, K., Misztak, P., Nowak, G., and Szewczyk, B. (2015). Antidepressant-like activity of magnesium in the olfactory bulbectomy model is associated with the AMPA/BDNF pathway. Psychopharmacology 232, 355-367. doi: 10.1007/s00213-014-3671-6 
Poleszak, E., Wlaź, P., Kedzierska, E., Nieoczym, D., Wróbel, A., Fidecka, S., et al. (2007). NMDA/glutamate mechanism of antidepressant-like action of magnesium in forced swim test in mice. Pharmacol. Biochem. Behav. 88, 158-164. doi: 10.1016/j.pbb.2007.07.018

Powell, T. R., Dima, D., Frangou, S., and Breen, G. (2018). Telomere length and bipolar disorder. Neuropsychopharmacology 43, 445-453. doi: 10.1038/npp. 2017.125

Prasad, A. S., and Bao, B. (2019). Molecular mechanisms of Zinc as a proantioxidant mediator: clinical therapeutic implications. Antioxidants 8:164. doi: 10.3390/antiox8060164

Prins, J., Olivier, B., and Korte, S. M. (2011). Triple reuptake inhibitors for treating subtypes of major depressive disorder: the monoamine hypothesis revisited. Expert Opin. Invest. Drugs 20, 1107-1130. doi: 10.1517/13543784.2011.594039

Pusceddu, M. M., El Aidy, S., Crispie, F., O'Sullivan, O., Cotter, P., Stanton, C., et al. (2015). N-3 polyunsaturated fatty acids (PUFAs) reverse the impact of early-life stress on the gut microbiota. PLoS One 10:e0139721. doi: 10.1371/journal.pone. 0139721

Pyndt Jørgensen, B., Winther, G., Kihl, P., Nielsen, D. S., Wegener, G., Hansen, A. K., et al. (2015). Dietary magnesium deficiency affects gut microbiota and anxiety-like behaviour in C57BL/6N mice. Acta Neuropsychiatr. 27, 307-311. doi: 10.1017/neu.2015.10

Qazi, T. J., Quan, Z., Mir, A., and Qing, H. (2018). Epigenetics in Alzheimer's disease: perspective of DNA methylation. Mol. Neurobiol. 55, 1026-1044. doi: 10.1007/s12035-016-0357-6

Qi, X. R., Zhao, J., Liu, J., Fang, H., Swaab, D. F., and Zhou, J. N. (2015). Abnormal retinoid and TrkB signaling in the prefrontal cortex in mood disorders. Cereb. Cortex 25, 75-83. doi: 10.1093/cercor/bht203

Ramaekers, V. T., Sequeira, J. M., and Quadros, E. V. (2016). The basis for folinic acid treatment in neuro-psychiatric disorders. Biochimie 126, 79-90. doi: 10. 1016/j.biochi.2016.04.005

Rao, T., Asha, M., Ramesh, B., and Jagannatha Rao, K. (2008). Understanding nutrition, depression and mental illnesses. Indian J. Psychiatry 50:77. doi: 10.4103/0019-5545.42391

Rapoport, S. I. (2014). Lithium and the other mood stabilizers effective in bipolar disorder target the rat brain arachidonic acid cascade. ACS Chem. Neurosci. 5, 459-467. doi: $10.1021 / \mathrm{cn} 500058 \mathrm{v}$

Reichmann, F., and Holzer, P. (2016). Neuropeptide Y: a stressful review. Neuropeptides 55, 99-109. doi: 10.1016/j.npep.2015.09.008

Réus, G. Z., Maciel, A. L., Abelaira, H. M., de Moura, A. B., de Souza, T. G., dos Santos, T. R., et al. (2018). $\omega$-3 and folic acid act against depressive-like behavior and oxidative damage in the brain of rats subjected to early- or late-life stress. Nutrition 53, 120-133. doi: 10.1016/j.nut.2018.03.006

Ribeiro, J. A., and Sebastio, A. M. (2010). Caffeine and adenosine. J. Alzheimers Dis. 20(Suppl. 1), S3-S15.

Romagnolo, D. F., Zempleni, J., and Selmin, O. I. (2014). Nuclear receptors and epigenetic regulation: opportunities for nutritional targeting and disease prevention. Adv. Nutr. 5, 373-385. doi: 10.3945/an.114.005868

Rosa, P. B., Ribeiro, C. M., Bettio, L. E. B., Colla, A., Lieberknecht, V., Moretti, M., et al. (2014). Folic acid prevents depressive-like behavior induced by chronic corticosterone treatment in mice. Pharmacol. Biochem. Behav. 121, 1-6. doi: 10.1016/j.pbb.2014.10.003

Ross, E. L., Vijan, S., Miller, E. M., Valenstein, M., and Zivin, K. (2019). The cost-effectiveness of cognitive behavioral therapy versus second-generation antidepressants for initial treatment of major depressive disorder in the United States a decision analytic model. Ann. Intern. Med. 171, 785-795. doi: $10.7326 / \mathrm{m} 18-1480$

Salzman, M. B., Smith, E. M., and Koo, C. (2002). Excessive oral zinc supplementation. J. Pediatr. Hematol. Oncol. 24, 582-584. doi: 10.1097/ 00043426-200210000-00020

Sarris, J., Mischoulon, D., and Schweitzer, I. (2012). Omega-3 for bipolar disorder: meta-analyses of use in mania and bipolar depression. J. Clin. Psychiatry 12, 207-227.

Sastry, P. S. (1985). Lipids of nervous tissue: composition and metabolism. Prog. Lipid Res. 24, 69-176. doi: 10.1016/0163-7827(85)90011-6

Saunders, E. F. H., Ramsden, C. E., Sherazy, M. S., Gelenberg, A. J., Davis, J. M., and Rapoport, S. I. (2016). Reconsidering dietary polyunsaturated fatty acids in bipolar disorder: a translational picture. J. Clin. Psychiatry 77, e1342-e1347.
Scalabrino, G., Corsi, M. M., Veber, D., Buccellato, F. R., Pravettoni, G., Manfridi, A., et al. (2002). Cobalamin (vitamin B12) positively regulates interleukin-6 levels in rat cerebrospinal fluid. J. Neuroimmunol. 127, 37-43. doi: 10.1016/ s0165-5728(02)00095-4

Schwalfenberg, G. K., and Genuis, S. J. (2017). The importance of magnesium in clinical healthcare. Scientifica 2017:4179326.

Serefko, A., Szopa, A., Wlaź, P., Nowak, G., Radziwoń-Zaleska, M., Skalski, M., et al. (2013). Magnesium in depression. Pharmacol. Rep. 65, 547-554.

Seto, E., and Yoshida, M. (2014). Erasers of histone acetylation: the histone deacetylase enzymes. Cold Spring Harb. Perspect. Biol. 6:a018713. doi: 10.1101/ cshperspect.a018713

Shabbir, F., Patel, A., Mattison, C., Bose, S., Krishnamohan, R., Sweeney, E., et al. (2013). Effect of diet on serotonergic neurotransmission in depression. Neurochem. Int. 62, 324-329. doi: 10.1016/j.neuint.2012.12.014

Sharpley, A. L., Hockney, R., McPeake, L., Geddes, J. R., and Cowen, P. J. (2014). Folic acid supplementation for prevention of mood disorders in young people at familial risk: a randomised, double blind, placebo controlled trial. J. Affect. Disord. 167, 306-311. doi: 10.1016/j.jad.2014.06.011

Shay, N. F., and Mangian, H. F. (2000). Neurobiology of Zinc-influenced eating behavior. J. Nutr. 130, 1493S-1499S.

Simopoulos, A. P. (1991). Omega-3 fatty acids in health and disease and in growth and development. Am. J. Clin. Nutr. 54, 438-463.

Singewald, N., Sinner, C., Hetzenauer, A., Sartori, S. B., and Murck, H. (2004). Magnesium-deficient diet alters depression- and anxiety-related behavior in mice - influence of desipramine and Hypericum perforatum extract. Neuropharmacology 47, 1189-1197. doi: 10.1016/j.neuropharm.2004. 08.010

Siwek, M., Dudek, D., Schlegel-Zawadzka, M., Morawska, A., Piekoszewski, W., Opoka, W., et al. (2010). Serum zinc level in depressed patients during zinc supplementation of imipramine treatment. J. Affect. Disord. 126, 447-452. doi: 10.1016/j.jad.2010.04.024

Siwek, M., Szewczyk, B., Dudek, D., Styczeñ, K., Sowa-Kuæma, M., Mlyniec, K., et al. (2013). Zinc as a marker of affective disorders. Pharmacol. Rep. 65, 1512-1518. doi: 10.1016/s1734-1140(13)71512-3

Slutsky, I., Abumaria, N., Wu, L. J., Huang, C., Zhang, L., Li, B., et al. (2010). Enhancement of learning and memory by elevating brain magnesium. Neuron 65, 165-177. doi: 10.1016/j.neuron.2009.12.026

Sona, C., Kumar, A., Dogra, S., Kumar, B. A., Umrao, D., and Yadav, P. N. (2018). Docosahexaenoic acid modulates brain-derived neurotrophic factor via GPR40 in the brain and alleviates diabesity-associated learning and memory deficits in mice. Neurobiol. Dis. 118, 94-107. doi: 10.1016/j.nbd.2018. 07.002

Song, C., Li, X., Leonard, B. E., and Horrobin, D. F. (2003). Effects of dietary n-3 or $\mathrm{n}-6$ fatty acids on interleukin- $1 \beta$-induced anxiety, stress, and inflammatory responses in rats. J. Lipid Res. 44, 1984-1991. doi: 10.1194/jlr.m300217-jlr200

Sowa-Kuæma, M., Legutko, B., Szewczyk, B., Novak, K., Znojek, P., Poleszak, E., et al. (2008). Antidepressant-like activity of zinc: Further behavioral and molecular evidence. J. Neural Trans. 115, 1621-1628. doi: 10.1007/s00702-0080115-7

Spasov, A. A., Iezhitsa, I. N., Kharitonova, M. V., and Kravchenko, M. S. (2008). Depression-like and anxiety-related behaviour of rats fed with magnesiumdeficient diet. Zh. Vyssh. Nerv. Deiat. Im. I P Pavlova 58, 476-485.

Squassina, A., Pisanu, C., Corbett, N., and Alda, M. (2017). Telomere length in bipolar disorder and lithium response. Eur. Neuropsychopharmacol. 27, 560-567. doi: 10.1016/j.euroneuro.2015.10.008

Starowicz, G., Jarosz, M., Frąckiewicz, E., Grzechnik, N., Ostachowicz, B., Nowak, G., et al. (2019). Long-lasting antidepressant-like activity of the GPR39 zinc receptor agonist TC-G 1008. J. Affect. Disord. 245, 325-334. doi: 10.1016/j.jad. 2018.11.003

Stilling, R. M., van de Wouw, M., Clarke, G., Stanton, C., Dinan, T. G., and Cryan, J. F. (2016). The neuropharmacology of butyrate: The bread and butter of the microbiota-gut-brain axis? Neurochem. Int. 99, 110-132. doi: 10.1016/j.neuint. 2016.06.011

Sublette, M. E., Bosetti, F., Demar, J. C., Ma, K., Bell, J. M., Fagin-jones, S., et al. (2007). Plasma free polyunsaturated fatty acid levels are associated with symptom severity in acute mania. Bipolar Disord. 9, 759-765. doi: 10.1111/j. 1399-5618.2007.00387.x 
Sun, C., Wang, R., Li, Z., and Zhang, D. (2019). Dietary magnesium intake and risk of depression. J. Affect. Disord. 246, 627-632. doi: 10.1016/j.jad.2018.12.114

Syed, E., Wasay, M., and Awan, S. (2013). Vitamin B12 supplementation in treating major depressive disorder: a randomized controlled trial. Open Neurol. J. 7, 44-48. doi: 10.2174/1874205x01307010044

Szewczyk, B., Kubera, M., and Nowak, G. (2011). The role of zinc in neurodegenerative inflammatory pathways in depression. Prog. Neuro Psychopharmacol. Biol. Psychiatry 35, 693-701. doi: 10.1016/j.pnpbp.2010.02. 010

Takeda, A. (2000). Movement of zinc and its functional significance in the brain. Brain Res. Rev. 34, 137-148. doi: 10.1016/s0165-0173(00)00044-8

Tang, M., Liu, Y., Wang, L., Li, H., Cai, H., Zhang, M., et al. (2018). An $\Omega-3$ fatty acid-deficient diet during gestation induces depressivelike behavior in rats: the role of the hypothalamo-pituitary-adrenal (HPA) system. Food Funct. 9, 3481-3488. doi: 10.1039/c7fo $01714 \mathrm{f}$

Tarleton, E. K., Kennedy, A. G., Rose, G. L., Crocker, A., and Littenberg, B. (2019). The association between serum magnesium levels and depression in an adult primary care population. Nutrients 11:1475. doi: 10.3390/nu11 071475

Tarleton, E. K., Littenberg, B., MacLean, C. D., Kennedy, A. G., and Daley, C. (2017). Role of magnesium supplementation in the treatment of depression: a randomized clinical trial. PLoS One 12:e0180067. doi: 10.1371/journal.pone. 0180067

Thesing, C. S., Bot, M., Milaneschi, Y., Giltay, E. J., and Penninx, B. W. J. H. (2018). Omega-3 polyunsaturated fatty acid levels and dysregulations in biological stress systems. Psychoneuroendocrinology 97, 206-215. doi: 10.1016/j.psyneuen. 2018.07.002

Thorsell, A. (2010). Brain neuropeptide $\mathrm{Y}$ and corticotropin-releasing hormone in mediating stress and anxiety. Exp. Biol. Med. 235, 1163-1167. doi: 10.1258/ ebm.2010.009331

Tomonaga, Y., Haettenschwiler, J., Hatzinger, M., Holsboer-Trachsler, E., Rufer, M., Hepp, U., et al. (2013). The economic burden of depression in Switzerland. PharmacoEconomics 31, 237-250. doi: 10.1007/s40273-013-0026-9

Trautmann, C., Bock, A., Urbach, A., Hübner, A., and Engmann, O. (2020a). Acute vitamin B12 supplementation evokes antidepressant response and alters Ntrk-2. Neuropharmacology 171:108112. doi: 10.1016/j.neuropharm.2020. 108112

Trautmann, C., Burek, D., Huebner, C., Girault, J., and Engmann, O. (2020b). A regulatory pathway linking caffeine action, mood and the circadian clock. Neuropharmacology 172:108133. doi: 10.1016/j.neuropharm.2020.10 8133

Trebaticka, J., Hradecna, Z., Surovcova, A., Katrencikova, B., Gushina, I., Waczulikova, I., et al. (2020). Omega-3 fatty-acids modulate symptoms of depressive disorder, serum levels of omega- 3 fatty acids and omega-6/omega3 ratio in children. Psychiatry Res. 287:112911. doi: 10.1016/j.psychres.2020. 112911

Tsujita, N., Akamatsu, Y., Nishida, M. M., Hayashi, T., and Moritani, T. (2019). Effect of tryptophan, vitamin b6, and nicotinamide-containing supplement loading between meals on mood and autonomic nervous system activity in young adults with subclinical depression: a randomized, double-blind, and placebo-controlled study. J. Nutr. Sci. Vitaminol. 65, 507-514. doi: 10.3177/ jnsv. 65.507

Ueland, P. M., McCann, A., Midttun, $\varnothing$, and Ulvik, A. (2017). Inflammation, vitamin B6 and related pathways. Mol. Aspects Med. 53, 10-27. doi: 10.1016/ j.mam.2016.08.001

van Calker, D., Biber, K., Domschke, K., and Serchov, T. (2019). The role of adenosine receptors in mood and anxiety disorders. J. Neurochem. 151, 11-27. doi: $10.1111 /$ jnc. 14841

van Calker, D., Müller, M., and Hamprecht, B. (1978). Adenosine inhibits the accumulation of cyclic AMP in cultured brain cells. Nature 276, 839-841. doi: $10.1038 / 276839 \mathrm{a} 0$

van Calker, D., Müller, M., and Hamprecht, B. (1979). Adenosine regulates via two different types of receptors, the accumulation of cyclic AMP in cultured brain cells. J. Neurochem. 33, 999-1005. doi: 10.1111/j.1471-4159.1979.tb 05236.x

Van Laecke, S. (2019). Hypomagnesemia and hypermagnesemia. Acta Clin. Belgica 74, 41-47. doi: 10.1080/17843286.2018.1516173 van Steenwyk, G., Gapp, K., Jawaid, A., Germain, P.-L., Manuella, F., Tanwar, D., et al. (2020). Involvement of circulating factors in the transmission of paternal experiences through the germline. EMBO J. 1:e104579.

Volpe, S. L. (2013). Magnesium in disease prevention and overall health. Adv. Nutr. 4:378S83S.

Vos, T., Abajobir, A. A., Abbafati, C., Abbas, K. M., Abate, K. H., Abd-Allah, F., et al. (2017). Global, regional, and national incidence, prevalence, and years lived with disability for 328 diseases and injuries for 195 countries, 1990-2016: a systematic analysis for the Global Burden of Disease Study 2016. Lancet 390, 1211-1259.

Walker, J. G., Batterham, P. J., Mackinnon, A. J., Jorm, A. F., Hickie, I., Fenech, M., et al. (2012). Oral folic acid and vitamin B-12 supplementation to prevent cognitive decline in community-dwelling older adults with depressive symptoms - the beyond ageing project: a randomized controlled trial. Am. J. Clin. Nutr. 95, 194-203. doi: 10.3945/ajcn.110. 007799

Wang, J., Um, P., Dickerman, B. A., and Liu, J. (2018). Zinc, magnesium, selenium and depression: a review of the evidence, potential mechanisms and implications. Nutrients 10:584. doi: 10.3390/nu10050584

Warden, D., Rush, A., Trivedi, M., Fava, M., and Wisniewski, S. (2007). The STAR*D project results: a comprehensive review of findings. Curr. Psychiatry Rep. 9, 449-459. doi: 10.1007/s11920-007-0061-3

Weitz, E. S., Hollon, S. D., Twisk, J., Van Straten, A., Huibers, M. J. H., David, D., et al. (2015). Baseline depression severity as moderator of depression outcomes between cognitive behavioral therapy vs pharmacotherapy: an individual patient data meta-analysis. JAMA Psychiatry 72, 1102-1109. doi: 10.1001/ jamapsychiatry.2015.1516

Wietrzych-Schindler, M., Szyszka-Niagolov, M., Ohta, K., Endo, Y., Pérez, E., De Lera, A. R., et al. (2011). Retinoid X receptor gamma is implicated in docosahexaenoic acid modulation of despair behaviors and working memory in mice. Biol. Psychiatry 69, 788-794. doi: 10.1016/j.biopsych.2010. 12.017

Wolkowitz, O. W., Epel, E. S., Reus, V. I., and Mellon, S. H. (2010). Depression gets old fast: do stress and depression accelerate cell aging? Depress. Anxiety 27, 327-338. doi: 10.1002/da.20686

Wu, X. Y., and Lu, L. (2012). Vitamin B6 deficiency, genome instability and cancer. Asian Pac. J. Cancer Prevent. 13, 5333-5338. doi: 10.7314/APJCP.2012.13.11. 5333

Wu, Y. Q., Dang, R. L., Tang, M. M., Cai, H. L., De Li, H., Liao, D. H., et al. (2016). Long chain omega-3 polyunsaturated fatty acid supplementation alleviates doxorubicin-induced depressive-like behaviors and neurotoxicity in rats: involvement of oxidative stress and neuroinflammation. Nutrients 8:243. doi: $10.3390 /$ nu 8040243

Yamada-Goto, N., Katsuura, G., Ochi, Y., Ebihara, K., Kusakabe, T., Sato-Asahara, N., et al. (2011). Amylin has an antidepressant action in diet-induced obesity. Obesity 19:S1

Yanaka, N., Koyama, T. A., Komatsu, S. I., Nakamura, E., Kanda, M., and Kato, N. (2005). Vitamin B6 suppresses NF-kappaB activation in LPS-stimulated mouse macrophages. Int. J. Mol. Med. 16, 1071-1075.

Yang, Y., Jing, X. P., Zhang, S. P., Gu, R. X., Tang, F. X., Wang, X. L., et al. (2013). High dose zinc supplementation induces hippocampal zinc deficiency and memory impairment with inhibition of BDNF signaling. PLoS One 8:e55384. doi: 10.1371/journal.pone.0055384

Yary, T., Lehto, S. M., Tolmunen, T., Tuomainen, T. P., Kauhanen, J., Voutilainen, S., et al. (2016). Dietary magnesium intake and the incidence of depression: A 20-year follow-up study. J. Affect. Disord. 193, 94-98. doi: 10.1016/j.jad.2015. 12.056

Yger, M., and Girault, J.-A. (2011). DARPP-32, jack of All trades? Master of which? Front. Behav. Neurosci. 5:56. doi: 10.3389/fnbeh.2011.00056

Yin, Y., Zhang, C., Wang, J., Hou, J., Yang, X., and Qin, J. (2015). Chronic caffeine treatment enhances the resilience to social defeat stress in mice. Food Funct. 6, 479-491. doi: 10.1039/c4fo00702f

Yu, S., and Reddy, J. K. (2007). Transcription coactivators for peroxisome proliferator-activated receptors. Biochim. Biophys. Acta Mol. Cell Biol. Lipids 1771, 936-951.

Yuan, H., Mischoulon, D., Fava, M., and Otto, M. W. (2018). Circulating microRNAs as biomarkers for depression: many candidates, few finalists. J. Affect. Disord. 233, 68-78. doi: 10.1016/j.jad.2017.06.058 
Zgórzyńska, E., Dziedzic, B., Gorzkiewicz, A., Stulczewski, D., Bielawska, K., Su, K. P., et al. (2017). Omega-3 polyunsaturated fatty acids improve the antioxidative defense in rat astrocytes via an Nrf2-dependent mechanism. Pharmacol. Rep. 69, 935-942. doi: 10.1016/j.pharep.2017. 04.009

Zhang, Q., Bai, B., Mei, X., Wan, C., Cao, H., Dan, L., et al. (2018). Elevated H3K79 homocysteinylation causes abnormal gene expression during neural development and subsequent neural tube defects. Nat. Commun. 9:3436.

Zhao, Y. J., Du, M. Y., Huang, X. Q., Lui, S., Chen, Z. Q., Liu, J., et al. (2014). Brain grey matter abnormalities in medication-free patients with major depressive disorder: a meta-analysis. Psychol. Med. 44, 2927-2937. doi: 10.1017/ s0033291714000518

Zheltova, A. A., Kharitonova, M. V., Iezhitsa, I. N., and Spasov, A. A. (2016). Magnesium deficiency and oxidative stress: an update. BioMedicine (Netherlands) 6, 20.
Zhernakova, A., Kurilshikov, A., Bonder, M. J., Tigchelaar, E. F., Schirmer, M., Vatanen, T., et al. (2016). Population-based metagenomics analysis reveals markers for gut microbiome composition and diversity. Science 352, 565-569. doi: $10.1126 /$ science.aad3369

Conflict of Interest: The authors declare that the research was conducted in the absence of any commercial or financial relationships that could be construed as a potential conflict of interest.

Copyright (c) 2020 Aly and Engmann. This is an open-access article distributed under the terms of the Creative Commons Attribution License (CC BY). The use, distribution or reproduction in other forums is permitted, provided the original author(s) and the copyright owner(s) are credited and that the original publication in this journal is cited, in accordance with accepted academic practice. No use, distribution or reproduction is permitted which does not comply with these terms. 